\title{
Advanced Applications for Underwater Acoustic Modeling
}

\author{
Paul C. Etter \\ Northrop Grumman Corporation, P.O. Box 1693, Baltimore, MD 21203, USA \\ Correspondence should be addressed to Paul C. Etter, paul.etter@ngc.com
}

Received 29 October 2011; Accepted 30 January 2012

Academic Editor: Jafar Saniie

Copyright ( 2012 Paul C. Etter. This is an open access article distributed under the Creative Commons Attribution License, which permits unrestricted use, distribution, and reproduction in any medium, provided the original work is properly cited.

\begin{abstract}
Changes in the ocean soundscape have been driven by anthropogenic activity (e.g., naval-sonar systems, seismic-exploration activity, maritime shipping and windfarm development) and by natural factors (e.g., climate change and ocean acidification). New regulatory initiatives have placed additional restrictions on uses of sound in the ocean: mitigation of marine-mammal endangerment is now an integral consideration in acoustic-system design and operation. Modeling tools traditionally used in underwater acoustics have undergone a necessary transformation to respond to the rapidly changing requirements imposed by this new soundscape. Advanced modeling techniques now include forward and inverse applications, integrated-modeling approaches, nonintrusive measurements, and novel processing methods. A 32-year baseline inventory of modeling techniques has been updated to reflect these new developments including the basic mathematics and references to the key literature. Charts have been provided to guide soundscape practitioners to the most efficient modeling techniques for any given application.
\end{abstract}

\section{Introduction}

Over the past several decades, the soundscape of the marine environment has responded to changes in both natural and anthropogenic influences. A soundscape is a combination of sounds that characterize, or arise from, an ocean environment. The study of a soundscape is sometimes referred to as acoustic ecology. The idea of a soundscape refers to both the natural acoustic environment (consisting of natural sounds including animal vocalizations, the sounds of weather, and other natural elements) and anthropogenic sounds (created by humans) including sounds of mechanical origin associated with the use of industrial technology. The disruption of the natural acoustic environment results in noise pollution.

This paper is concerned with the underwater soundscape. The field of underwater acoustics enables us to observe quantitatively and predict the behavior of this soundscape and the response of the natural acoustic environment to noise pollution. Specifically, underwater acoustics entail the development and employment of acoustical methods to image underwater features, to communicate information via the oceanic waveguide, or to measure oceanic properties. In the present context, underwater acoustics encompasses both the science and the technology necessary to deploy functioning acoustical systems in support of naval and commercial operations.

Broadly defined, modeling is a method for organizing knowledge accumulated through observation or deduced from underlying principles. Modeling applications fall into two basic categories: prognostic and diagnostic. Prognostic applications include prediction and forecasting functions where future oceanic conditions or acoustic sensor performance must be anticipated. Diagnostic applications include system-design and analysis functions typically encountered in engineering tradeoff studies.

The challenges of managing the underwater soundscape are being met by enabling technologies and by emerging solutions. Throughout this paper, the utility of the available inventory of models is stressed and relevant examples from the recent literature are provided in support.

After a brief background in Section 1, the balance of this paper is divided into three main sections. Section 2 addresses evolving challenges. Section 3 discusses enabling technologies. Section 4 reviews emerging solutions. Finally, Section 5 summarizes the notable advances in underwater acoustic modeling that support management of the underwater soundscape. 


\section{Evolving Challenges}

2.1. Background. The soundscape baseline is defined by ambient noise, which is the prevailing background of sound at a particular location in the ocean at a given time of the year. It does not include transient sounds such as the noise of nearby ships and marine organisms, or of passing rain showers. In practice, ambient noise excludes all forms of selfnoise, such as the noise of current flow around the sonar. For sonar processing, however, it is the background of noise (including interfering sounds), typical of the time, location, and depth against which an acoustic signal must be detected.

\subsection{Naval Operations in Coastal Environments}

2.2.1. The Coastal Environment. Coastal environments are generally characterized by high spatial and temporal variabilities. When coupled with attendant acoustic spectral dependencies of the surface and bottom boundaries, these natural variabilities make coastal regions very complex acoustic environments. Specifically, changes in the temperature and salinity of coastal waters affect the refraction of sound in the water column. These refractive properties have a profound impact on the transmission of acoustic energy in a shallowwater waveguide with an irregular bottom and a statistically varying sea surface. Thus, accurate modeling and prediction of the acoustic environment is essential to understanding sonar performance in coastal oceans.

Physical processes controlling the hydrography of shelf waters often exhibit strong seasonal variations. Annual cycles of alongshore winds induce alternating periods of upwelling and downwelling. The presence of coastal jets and the frictional decay of deep-water eddies due to topographic interactions further complicate the dynamics of coastal regions. Episodic passages of meteorological fronts from continental interiors affect the thermal structure of the adjacent shelf waters through intense air-sea interactions. River outflows create strong salinity gradients along the adjacent coast. Variable bottom topographies and sediment compositions with their attendant spectral dependencies complicate acoustic bottom boundary conditions. At higher latitudes, ice formation complicates acoustic surface boundary conditions near the coast. Waves generated by local winds under fetch-limited conditions, together with swells originating from distant sources, conspire to complicate acoustic surface boundary conditions and also create noisy surf conditions. Marine life, which is often abundant in nutrient-rich coastal regions, can generate or scatter sound. Anthropogenic sources of noise are common in coastal seas including fixed sources such as drilling rigs and mobile sources such as merchant shipping and fishing vessels. Surface weather, including wind and rain, further contribute to the underwater noise field. Even noise from low-flying coastal aircraft can couple into the water column and add to the background noise field.

2.2.2. Littoral Operations. Over the past decade, naval mission requirements have shifted from open-ocean operations to shallow-water (or littoral) scenarios. For convenience, shallow water will be defined by water depths less than 200 meters. This has not been an easy transition for sonar technologists since sonar systems that were originally designed for operation in deep water seldom work optimally in coastal regions. This has also held true for modeling and simulation (M\&S) technologies, which have undergone a redefinition and refocusing to support a new generation of multistatic naval systems that are intended to operate efficiently in littoral regions while still retaining a deepwater capability. Shallow-water geometries increase the importance of boundary interactions, which diminish acoustic energy through scattering and also complicate localization of diesel submarines and coastal mines due to multipath propagation. Moreover, the higher levels of interfering noises encountered in coastal regions combined with higher levels of boundary reverberation mask signals of interest. In advance of naval deployments, synoptic meteorological and oceanographic (METOC) measurements are often required in remote or hostile (i.e., harsh or heavily defended) coastal environments to forecast acoustic sensor performance. Coupled atmosphere-ocean-acoustic models could reduce the need for hazardous in situ data collection by numerically computing initial states for the embedded acoustic models.

In support of naval operations in littoral regions, acoustical oceanographers have employed ocean-acoustic models as adjunct tools that can be used to conduct rapid environmental assessments (REAs) in remote locations. Due to an increased awareness of the potential technological impacts on marine life, naval commanders and acoustical oceanographers must also be aware of new environmental regulations governing the acoustic emissions of their sonar systems.

In shallow water, interactions of the acoustic fields with the sea bed require an understanding of the sedimentary structure of the bottom to a level of detail that is usually not required in deep-water environments. In the forwardpropagation case, this means that a significant amount of information is necessary to properly characterize the bottom boundary to ensure the generation of high-fidelity model outputs. This generally requires a good understanding of the physics of bottom-interacting acoustics in diverse ocean environments.

Sonar clutter, particularly in shallow-water environments, introduces false targets that change the statistics of the reverberation signal. Specifically, clutter increases the probability of false alarm for a given probability of detection. This is because clutter adds to the length of the tails of the reverberation-envelope PDF (probability distribution function), moving the statistics away from the Rayleigh canonical form. Clutter can be caused by target-like features, either natural or man-made, or by non-Gaussian distributions of the scatterers. Typically, high-bandwidth or highly directive systems (or both) have more problems with clutter since, as the size of the scattering patch is reduced, the PDF of the generally non-Gaussian scatterer distributions becomes resolved by the system [1].

2.2.3. Training Ranges. At issue here is operational naval training with active sonars. These high-power multistatic 
sonars have become more important in the face of improved diesel-electric submarine threats operating in complex coastal environments.

The US Navy has explored the environmental consequences of installing and operating an undersea warfare training range (USWTR) in conjunction with appropriate coordination and consultation with the National Marine Fisheries Service (NMFS) and in compliance with applicable laws and executive orders including the Marine Mammal Protection Act (MMPA), the Endangered Species Act (ESA), the National Environmental Policy Act (NEPA), and the Coastal Zone Management Act (CZMA).

2.2.4. Underwater Networks. Ocean-bottom sensor nodes are used for oceanographic data collection, pollution monitoring, offshore exploration, tactical surveillance applications, and rapid environmental assessments [2, 3]. Factors that determine the temporal and spatial variability of the acoustic channel also limit the available bandwidth of the ocean channel and make it dependent on range and frequency. Specifically, long-range systems $(\sim 10 \mathrm{~km})$ have bandwidths of a few kilohertz while short-range systems $(\sim 0.1 \mathrm{~km})$ have bandwidths on the order of a hundred kilohertz. A mooredbuoy ocean observatory system comprising oceanographic sensors was linked by acoustic communications to retrieve data from sensors in the water column at ranges of approximately $3 \mathrm{~km}$ [4]; the observatory was deployed off Vancouver Island in the northeastern Pacific Ocean in May 2004 (for 13 months) to study the correlation of seismicity and fluid flow in a seep area along the Nootka fault.

Underwater networks consist of variable numbers of sensors and vehicles deployed in concert to perform collaborative monitoring tasks over a given area. Underwater sensor networks comprise nodes that communicate via acoustic waves over multiple wireless hops to perform collaborative tasks such as environmental monitoring, naval surveillance, and oceanic exploration. Nodes in underwater sensor networks are constrained by harsh physical environments. Data delivery schemes originally designed for terrestrial sensor networks are unsuitable for use in the underwater environment. Relatively few new schemes have been proposed for underwater use, and no single scheme has yet emerged as the de facto standard.

Underwater acoustic communications are influenced by spreading loss, noise, multipath discrimination, Doppler spread, and high and variable propagation delays. Moreover, underwater acoustic channels normally have low data rates and time-varying fading. These factors determine the temporal and spatial variability of the acoustic channel and make the available bandwidth of the ocean channel both limited and dependent on range and frequency. Challenges due to the presence of fading, multipath, and refractive properties of the sound channel necessitate the development of precise underwater-channel models. Some existing channel models are simplified and do not consider multipaths or fading. Multipath interference due to boundary reflection in shallow-water acoustic communications poses major obstacles to reliable high-speed underwater communication systems.
Cooperative transmission is a new wireless communication technique in which diversity gain can be achieved by utilizing relay nodes as virtual antennae. These transmission techniques have been investigated for underwater acoustic communications. First, the performance of several cooperative transmission schemes was studied in an underwater scenario. Second, by taking advantage of the relatively low propagation speed of sound in water, a new wave cooperative transmission scheme was designed in which the relay nodes amplified the signal received from the source node and then forwarded the signal immediately to the intended destination. The goal was to alter the multipath effect at the receiver. Third, the upper bound of performance was derived for the proposed wave cooperative transmission scheme. The simulation results showed that the proposed wave cooperative transmission had significant advantages over both the traditional direct transmission and the existing cooperative transmission schemes originally designed for radio wireless networks [5].

Localization algorithms are relevant to underwater sensor networks, but there are challenges in meeting requirements imposed by emerging applications for such networks in offshore engineering [6]. Localization algorithms can be broadly categorized into range-based and range-free schemes. Range-based schemes use precise distance or angle measurements to estimate the location of nodes in a network. Rangefree schemes are simpler than range-based schemes, but they only provide a coarse estimate of a node's location.

Underwater networking is an enabling technology for the operation of autonomous underwater vehicles. In particular, ad hoc networks entail wireless communications for mobile hosts called nodes. In these networks, there is no fixed infrastructure. Mobile nodes that are within range communicate directly via wireless links, while those that are far apart rely on other nodes to relay messages as routers. Node mobility in an ad hoc network causes frequent changes of the network topology. Since ad hoc networks can be deployed rapidly with relatively low cost, they are attractive for military, emergency, commercial and scientific applications [2, 3]. A channel simulator was developed for testing the performance of unmanned undersea vehicle (UUV) communications [7].

2.2.5. Unmanned Underwater Vehicles. Autonomous underwater vehicles (AUVs), or unmanned undersea vehicles (UUVs), constitute part of a larger group of undersea systems known as unmanned underwater vehicles, a classification that includes nonautonomous remotely operated vehicles (ROVs) that are controlled and powered from the surface by an operator (or pilot) via an umbilical connection.

Underwater gliders actually constitute a new class of autonomous underwater vehicles that glide by controlling their buoyancy and attitude using internal actuators [8]. Gliders have useful applications in oceanographic sensing and data collection because of their low cost, autonomy, and capability for long-range extended-duration deployments. They serve as adjuncts to ship-based hydrographic casts, towed sensors, UUV/AUV and satellite-based sensors, but they also present challenges in communications common to all untethered subsurface sensors. 


\subsection{Marine Seismic Operations}

2.3.1. Seismic Exploration. Marine seismic surveys are used to assess the location of hydrocarbon resources, including gas and oil. There are two acquisition methods: 2D and 3D. The 2D method tows a single seismic cable (or streamer) behind the seismic vessel, together with a single source. The reflections from the subsurface of the sea floor are assumed to lie directly below the path (sail line) of the vessel. In a 3D survey, groups of sail lines (or swathes) are used to acquire orthogonal or oblique lines relative to the acquisition direction. By utilizing more than one source together with many parallel streamers towed by the seismic vessel, the acquisition of many closely spaced subsurface 2D lines can be achieved by a single sail line. Computationally intensive processing is necessary to produce a 3D image of the subsurface of the sea floor. The source arrays are powered by high-pressure air that is compressed onboard the seismic vessel. These compressors are capable of recharging the airguns rapidly and continuously, enabling the airgun source arrays to be fired at approximately 10-second intervals for periods of up to 12 hours. Typical towing depths range from 4-5 meters for shallow high-resolution surveys or 810 meters for deeper penetration, lower-frequency targets in open waters. Typical source outputs are approximately $220 \mathrm{~dB}$ re $1 \mu \mathrm{Pa} / \mathrm{Hz}$ at $1 \mathrm{~m}$. Other types of seismic sources include water guns and marine vibrators.

2.3.2. Marine Mammal Impacts. In 2002, the International Association of Geophysical Contractors (IAGC) hosted an informal meeting to discuss future Acoustics Research relevant to seismic operations related to the effects of seismic exploration on sperm whales in the Gulf of Mexico [9]. The IAGC offered its support for sperm-whale research through the contribution of a seismic-source vessel for controlled-exposure experiments. In response, a proposed sperm whale seismic study (SWSS) was approved by the Minerals Management Service (MMS) in 2002. (The MMS is now the Bureau of Ocean Energy Management, Regulation and Enforcement, or BOEMRE.) In subsequent years, IAGC was joined by a number of oil and gas companies to form the Industry Research Funders Coalition (IRFC) that has continued to provide contributions in support of SWSS studies.

Long-term (monthly to seasonal) movements and distributions of sperm whales were studied using satellite-tracked radio telemetry tags (S-tags). Short-term (hours) diving and swimming behavior and vocalizations of sperm whales were examined using recoverable digital-recording acoustic tags (D-tags) that logged whale orientation (i.e., pitch, roll, heading) and depth, as well as the sounds made by the whale and received at the whale from the environment. Diving depths and movements were examined using 3D passive acoustic tracking techniques.

To examine potential changes in the behavior of sperm whales when subjected to seismic airgun sounds, controlled exposure experiments (CEEs) were conducted using the Dtags in conjunction with a seismic-source vessel. The location and level of airgun sounds delivered at the tagged sperm whales were controlled by the science team. These CEEs provided data on the immediate and short-term (hours) response of sperm whales to airgun sounds. Longer-term avoidance or displacement behaviors of sperm whales to seismic vessel airgun sounds were examined using location data from the S-tags and from proprietary commercial seismic shot data.

The 3D tracking method requires at least two widely separated hydrophones to obtain the horizontal range and depth of acoustically active sperm whales and would thus be suited for eventual use on a standard seismic vessel, where the passive acoustic arrays (streamers) can be over a kilometer long. Instead of relying on four hydrophones deployed as a three-dimensional array (which would be difficult to deploy and process), the method used here exploited surface multipath (or "ghosts") to reduce the number of required hydrophones to three and further permitted the phones to be deployed along a single towed cable. The horizontal separation between the widely-spaced hydrophones needed to be at least $200 \mathrm{~m}$ in order to obtain adequate range and depth resolution at $1 \mathrm{~km}$ horizontal ranges. The method did not require the use of multipath from the ocean bottom, but when such bottom returns were detected they could provide an independent confirmation of these tracking procedures [10].

2.4. Shipping Activity. Shipping lanes, a term used to indicate the general flow of merchant traffic between two ports, are routes that historically have been optimized for shortest distances and travel times, and which are modified to avoid extreme weather events [11]. Noise from distant shipping generally occupies the frequency band $20-500 \mathrm{~Hz}$.

A comparison of time-series measurements of ocean ambient noise over two periods (1963-1965 and 19942001) revealed that noise levels from the latter period exceeded those of the earlier period by about $10 \mathrm{~dB}$ in the frequency ranges $20-80 \mathrm{~Hz}$ and $200-300 \mathrm{~Hz}$, and by about $3 \mathrm{~dB}$ at $100 \mathrm{~Hz}$ [12]. The observed increase was attributed to increases in shipping. Ambient noise measurements collected at the same site but separated by an interval of nearly 40 years (1964-1966 and 2003-2004) revealed an average noise increase of $2.5-3 \mathrm{~dB}$ per decade in the frequency band 30$50 \mathrm{~Hz}[13,14]$.

2.5. Windfarm Development. Wind power, as an alternative to fossil fuels, is plentiful, renewable, widely distributed, clean, and produces no greenhouse gas emissions during operation. A wind farm, which is a group of wind turbines in the same location used for production of electric power, may be located offshore. The installation of ocean wind farms requires medium water depths $(<30 \mathrm{~m})$ and construction logistics such as access to specialized vessels to install the turbines. Economic wind generators require wind speeds of $16 \mathrm{~km} / \mathrm{h}$ or greater.

A concerted effort has been made by industry to minimize any undesirable effects relating to windfarm development and operation [15]. One potential effect of offshore windfarm development is the creation of underwater noise. 
Knowing the length of time the marine environment is exposed to an underwater noise source is useful when assessing environmental effects. Measurements of offshore wind turbine noise showed low-frequency sound levels with a maximum of $153 \mathrm{~dB}$ re $1 \mu \mathrm{Pa}$ at $1 \mathrm{~m}$ at $16 \mathrm{~Hz}$. These measurements were of individual turbines of a relatively low power (less than 1MW). Despite the low-level and low-frequency nature of the sound, behavioral reactions of marine mammals have been observed in response to the reproduction of wind-turbine noise.

2.6. Ocean Acidification. Climate change also affects the ocean soundscape. The emission of carbon into the atmosphere through the effects of fossil-fuel combustion and industrial processes increases atmospheric concentrations of carbon dioxide $\left(\mathrm{CO}_{2}\right)$. Ocean acidification, which occurs when $\mathrm{CO}_{2}$ in the atmosphere reacts with water to create carbonic acid $\left(\mathrm{H}_{2} \mathrm{CO}_{3}\right)$, is increasing.

The attenuation of low-frequency sound in the sea is $\mathrm{pH}$ dependent; specifically, the higher the $\mathrm{pH}$, the greater the attenuation. Thus, as the ocean becomes more acidic (lower $\mathrm{pH}$ ) due to increasing $\mathrm{CO}_{2}$ emissions, the attenuation will diminish and low-frequency sounds will propagate farther, making the ocean noisier.

Recent investigations modeled what effect the increasing acidity of the ocean would have on ambient-noise levels in shallow water in the presence of internal waves [16]. This model assumed an isotropic distribution of noise sources. Exploring a scenario typical of the East China Sea, the noise at $3 \mathrm{kHz}$ was predicted to increase by $30 \%$, or about one decibel, as the $\mathrm{pH}$ decreased from 8.0 to 7.4. These results are representative of other contemporaneous investigations into this matter.

\section{Enabling Technologies}

\subsection{Background}

3.1.1. Regulatory Initiatives. An examination of anthropogenic sound in a global context considered the need for new regulatory initiatives to deal with the conflicting uses of ocean space related to noise [17]. This study identified the existing legal, economic, and political barriers to the creation and implementation of a new international regime designed to manage anthropogenic noise in the ocean.

The Committee on Potential Impacts of Ambient Noise in the Ocean on Marine Mammals was charged by the Ocean Studies Board of the US National Research Council to assess the state of our knowledge of underwater noise and recommend research areas to assist in determining whether noise in the ocean adversely affects marine mammals [18]. One of the findings of this committee was that models describing ocean noise are better developed than are models describing marine mammal distribution, hearing, and behavior. The biggest challenge lies in integrating the two types of models. The National Research Council [19] also examined what constitutes biologically significant in the context of Level $\mathrm{B}$ harassment as used in the latest amendments to the
US Marine Mammal Protection Act (MMPA). The MMPA separates harassment into two levels. Level A harassment is defined as "any act of pursuit, torment, or annoyance which has the potential to injure a marine mammal or marine mammal stock in the wild." Level B harassment is defined as "any act of pursuit, torment, or annoyance which has the potential to disturb a marine mammal or marine mammal stock in the wild by causing disruption of behavioral patterns, including, but not limited to, migration, breathing, nursing, breeding, feeding, or sheltering." The MMPA, enacted in 1972, was the first legislation that called for an ecosystem approach to natural-resource management and conservation; it specifically prohibited the take (i.e., hunting, killing, capture, and/or harassment) of marine mammals.

The ocean biogeographic information system (OBIS) is an on-line worldwide atlas for accessing, modeling and mapping marine biological data in a multidimensional geographic context [20]. Also see the website at http://www.iobis.org/home.

3.1.2. Modeling Uncertainty. Uncertainty has been defined as a quantitative measure of our lack of knowledge of the sound-speed field and boundary conditions constituting the waveguide information necessary for simulation of the acoustic field [21]. This uncertainty is distinct from any errors related to numerical solution of the wave equation. Existing methods typically solve a deterministic wave equation separately over many realizations, and the resulting set of pressure fields is then used to estimate statistical moments of the field. Proper sampling may involve the computation of thousands of realizations to ensure convergence of the statistics.

A study of the effects of uncertainty in the modeling of anthropogenic impacts suggested a precautionary approach to regulation [22]. It was further noted that due to the complex patterns of sound propagation encountered in diverse shelf regions, some marine mammals may not necessarily encounter the average sound exposure conditions predicted for any given seismic survey.

3.2. Numerical Modeling Techniques. Four types of models will be discussed: propagation, noise, reverberation, and sonar performance. The order of presentation will follow that indicated in Figure 1. This box-type format will be used throughout the text to present compact summaries of methods that have been developed in detail elsewhere [23].

3.2.1. Propagation Models. As sound propagates through the ocean, the effects of spreading and attenuation diminish its intensity. Spreading loss includes spherical and cylindrical spreading losses in addition to focusing effects. Attenuation loss includes losses due to absorption, leakage out of ducts, scattering, and diffraction. Propagation losses increase with increasing frequency due largely to the effects of absorption. Sound propagation is profoundly affected by the conditions of the surface and bottom boundaries of the ocean as well as by the variation of sound speed within the ocean volume. 


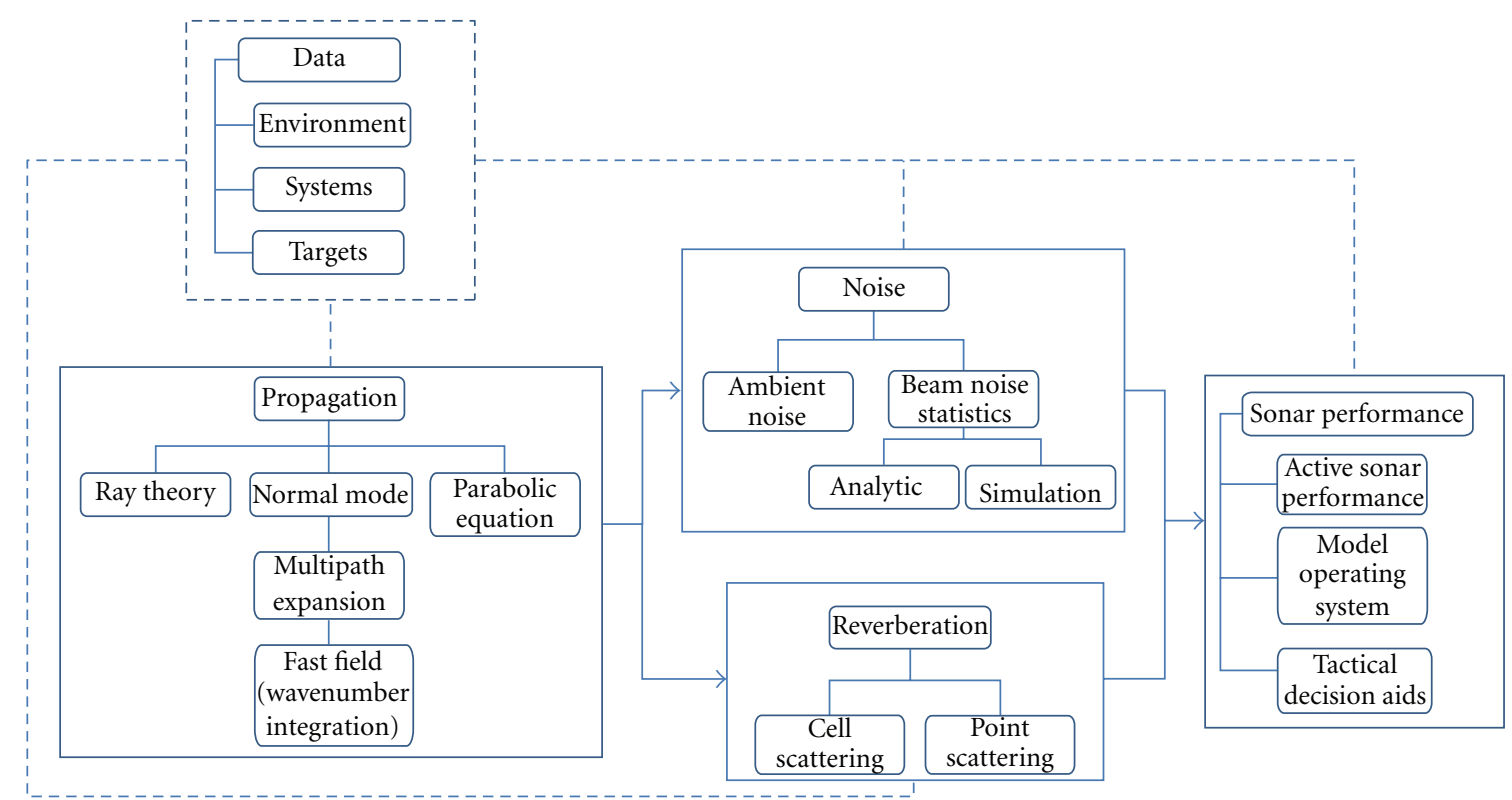

FIGURE 1: Flow of underwater acoustic modeling from propagation, through noise and reverberation, to sonar performance.

Sound-speed gradients introduce refractive effects that may focus or defocus the propagating acoustic energy.

Formulations of acoustic propagation models generally begin with the three-dimensional, time-dependent wave equation. For most applications, a simplified linear, hyperbolic, second-order, time-dependent partial differential equation is used:

$$
\nabla^{2} \Phi=\frac{1}{c^{2}} \frac{\partial^{2} \Phi}{\partial t^{2}}
$$

where $\nabla^{2}=\left(\partial^{2} / \partial x^{2}\right)+\left(\partial^{2} / \partial y^{2}\right)+\left(\partial^{2} / \partial z^{2}\right)$ is the Laplacian operator, $\Phi$ is the potential function, $c$ is the speed of sound, and $t$ is the time.

Subsequent simplifications incorporate a harmonic (single-frequency, continuous wave) solution in order to obtain the time-independent Helmholtz equation. Specifically, a harmonic solution is assumed for the potential function $\Phi$ :

$$
\Phi=\phi e^{-i \omega t}
$$

where $\phi$ is the time-independent potential function, $\omega$ is the source frequency $(2 \pi f)$, and $f$ is the acoustic frequency. Then the wave equation (1) reduces to the Helmholtz equation:

$$
\nabla^{2} \phi+k^{2} \phi=0
$$

where $k=(\omega / c)=(2 \pi / \lambda)$ is the wavenumber and $\lambda$ is the wavelength. Equation (3) is referred to as the timeindependent (or frequency-domain) wave equation.

Propagation models are integral to the higher-level modeling of noise, reverberation, and, ultimately, sonar performance. The graphic in Figure 1 shows the flow of sonar modeling from propagation, through noise and reverberation, through to sonar performance. Estimates of passive sonar performance would require the input of propagation and noise while active sonar performance would require inputs of both noise and reverberation.

Propagation models can be categorized into five distinct techniques [23].

(a) Ray-theoretical models calculate propagation loss on the basis of ray tracing.

(b) Normal-mode solutions are derived from an integral representation of the wave equation.

(c) Multipath expansion techniques expand the acoustic field integral representation of the wave equation in terms of an infinite set of integrals, each of which is associated with a particular ray-path family. Thus, each normal mode can then be associated with corresponding rays.

(d) In underwater acoustics, fast-field theory is also referred to as "wavenumber integration." In seismology, this approach is commonly referred to as the "reflectivity method" or "discrete-wavenumber method."

(e) The parabolic approximation approach replaces the elliptic reduced wave equation with a parabolic equation (PE). Use of the parabolic approximation in wave propagation problems can be traced back to the mid-1940s when it was first applied to long-range tropospheric radio wave propagation.

As shown in Figure 2, a further division can be made according to range-independent (1D, or depth-dependence only) or range-dependent environmental specifications, where environmental range-dependence can be 2D (depth and range) or 3D (depth, range, and azimuth). Since all five techniques are derived from the wave equation by restricting solutions to the frequency domain, the resulting models 


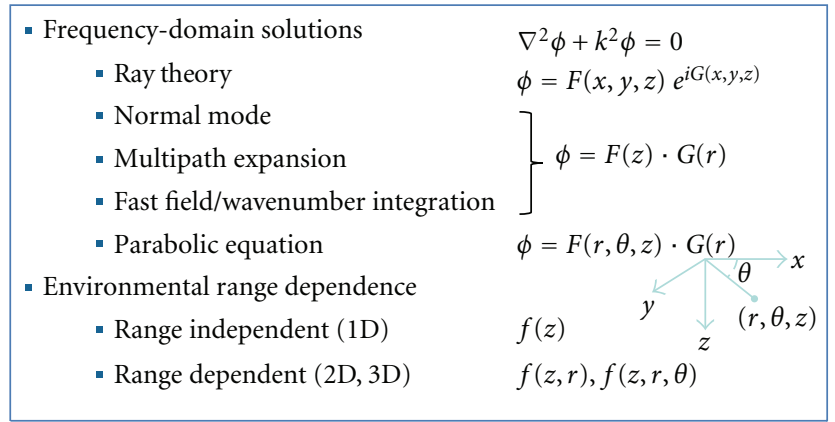

FIGURE 2: Organization of propagation models into five distinct techniques. A further division is made according to range-independent (1D) or range-dependent (2D or 3D) environmental specifications.

are appropriate for traditional sonar applications. (Solutions obtained in the time domain would be appropriate, e.g., for modeling shock propagation in the ocean.) Each of the five techniques has a unique domain of applicability that can be defined in terms of acoustic frequency and environmental complexity. These domains are determined by the assumptions that were invoked in deriving each solution. Hybrid formulations obtained by combining two or more different techniques are often developed to improve domain robustness.

Table 1 provides a summary of stand-alone propagation models. Superscript letters identify those models that have been added to the inventory since 2003. These letters refer to a brief summary and appropriate documentation. Model documentation can range from informal programming commentaries to journal articles to detailed technical reports containing a listing of the actual computer code. Corresponding information on the legacy models is provided in the 2003 baseline [23] and is not repeated here.

In Table 1: (Propagation models), (a) FeyRay was developed to accommodate the speed, fidelity, and implementation requirements of sonar trainers and simulators. It is a broadband, range-dependent, point-to-point propagation model optimized for computa-tional efficiency. FeyRay utilizes the Gaussian-beam approximation, which reduces the acoustic wave equation (a partial differential equation) to a more tractable system of ordinary differential equations [24-28], (b) PlaneRay provides a unique sorting and interpolation routine for efficient determination of a large number of eigenrays in range-dependent environments. No rays are traced into the bottom since bottom interaction is modeled by plane-wave reflection coefficients. The bottom structure is modeled as a fluid sediment layer over a solid half-space. This approach balances two conflicting requirements: ray tracing is valid for high frequencies while plane-wave reflection coefficients are valid for low frequencies where the sediment layers are thin compared with the acoustic wavelength [29-33], (c) PWRC is a ray-based model that performs geoacoustic inversions in range-dependent ocean waveguides. The pressure field is modeled approximately by separating the ocean propagation ray paths from the layered bottom interaction. The bottom interaction is included by using a full-wave description, making PWRC a hybrid model, in contrast to a full-ray theory approach that traces rays into the bottom layers. The field contribution from the bottom interactions partially includes beam-displacement effects associated with internally reflected or refracted returns from the sediment since the complex bottom reflection coefficients are obtained from a full-wave solution. This method is comparable in accuracy to normal mode and analytic solutions (in range-dependent environments) for frequencies $>100 \mathrm{~Hz}$ [34], (d) Ray5, developed by Trond Jenserud at the Forsvarets forskningsinstitutt (Norwegian Defence Research Establishment), uses direct integration in a sound-speed field specified either analytically or by interpolation from measured data. The Ray5 program is well suited for ray-tracing calculations in acoustic fields described analytically. It needs the sound-speed values, their spatial derivatives and second derivatives at all points within the field. Hence, if these values can be given analytically as functions of the oceanographic and bathymetric parameters, no interpolation is necessary and the program reduces its computing time. Further developments in Ray5 have made it possible to calculate eigenrays. This allows phase information to be retained for a given frequency so that coherent pressure values can be summed for the rays arriving at the receiver. The actual pressure values for the individual rays are calculated by assuming the pressure distribution in the direction normal to the ray to have a Gaussian behavior (i.e., Gaussian beams). It is also possible to calculate the incoherent sound levels [35]. A separate report includes the MATLAB code for Ray5 [36], (e) RAYSON was developed by Semantic (France) to solve the Helmholtz equation using a ray-theoretic approximation for high frequencies. In a stratified (range-independent) environment, analytic solutions are obtained for ray paths that are portions of circles. In range-dependent environments, the ray equations are numerically integrated using a fourth-order Runge-Kutta method to propagate the rays along the range axis. The bottom composition can vary with range and the state of the sea surface can vary in time as well as in range. The software is coded in C++ and is available commercially [37-40], (f) XRAY combines ray tracing in a range-dependent water column with local full-field modeling of interactions with a seabed composed of multiple range-dependent layers of fluid 


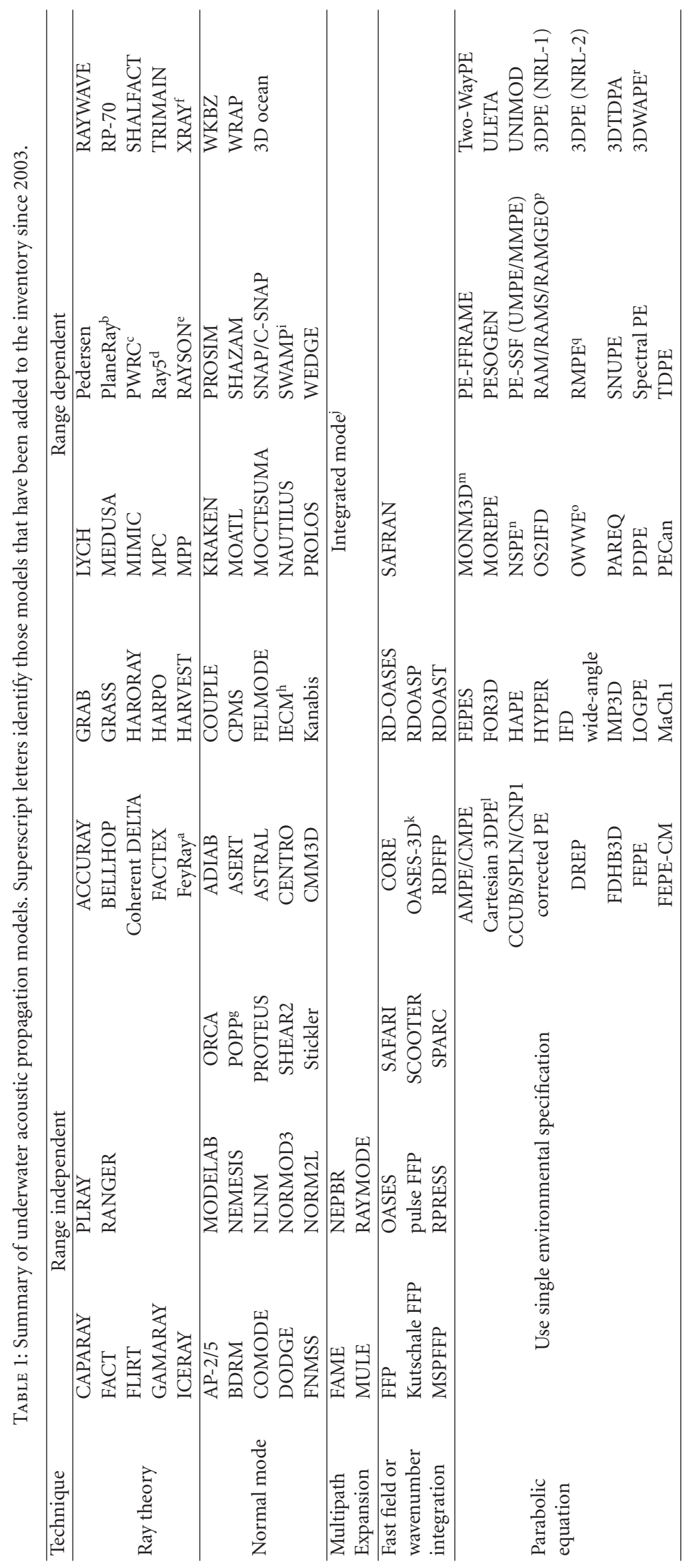


or solid materials [41], (g) POPP is a range-independent version of the PROLOS normal-mode propagation model [42], (h) IECM is a two-way coupled-mode formalism that provides an exact solution to the wave equation [43]. This model was used to establish a benchmark solution that is an exact numerical solution for the reverberation time series for an environment with a range-dependent, fine-scale rough bottom boundary that induces mode coupling and generates a scattered field. The solution includes scattering effects to all orders in that it sums the infinite series of forward and backward contributions at each range point and maintains energy conservation, (i) SWAMP is a range-dependent normal-mode model that contains closed-analytical forms of the vertical mode functions, which facilitate computation of one-way mode-coupling coefficients between adjacent range-independent regions by neglecting weak backscattering components [44, 45]. The model was used to understand the physics of pulse propagation in double-ducted shallow-water environments where precursors have been observed. The pulse temporal response is modeled using Fourier synthesis in the frequency domain. The model accounts for scattering events along the acoustic signal propagation path and has been extended to model acoustic pulse scattering by spherical elastic-shell targets in inhomogeneous waveguides within the T-matrix approach [46], (j) Integrated Mode extends the multipath expansion method to range-dependent environments [47]. This approach accounts for horizontal variations in bottom depth, bottom type, and sound speed using the stationary phase approximation, (k) OASES-3D target modeling framework is used to investigate scattering mechanisms of flush buried spherical shells under evanescent insonification [48-51], (l) The Cartesian 3D parabolic equation program implements a split-step Fourier algorithm with a wide-angle $\mathrm{PE}$ approximation, and is thus a $3 \mathrm{D}$ variant of the $\mathrm{PE}$ model of Thomson and Chapman [52]. The advantage of employing Cartesian coordinates in the numerical scheme is that the model resolution is uniform over the computational domain [53, 54], (m) MONM3D incorporates techniques that reduce the required number of model grid points. The concept of tessellation (i.e., covering the plane with a pattern in such a way as to leave no region uncovered) is used to optimize the radial grid density as a function of range, reducing the required number of grid points in the horizontal planes of the grid. The model marches the solution out in range along several radial propagation paths emanating from a source position. Tessellation, as implemented in MONM3D, allows the number of radial paths in the model grid to depend on range from the source. In addition, the model incorporates a higherorder azimuthal operator which allows a greater radial separation and reduces the required number of radial propagation paths [55], (n) NSPE, the Navy Standard PE model, consists of two methods of solving the acoustic parabolic wave equation: split-step Fourier parabolic equation model (SSFPE); and split-step Padé (finiteelement) parabolic equation (SSPPE) known as RAM. [http://www.nrl.navy.mil/content.php?P=03REVIEW212],

(o) OWWE [56] is based on the innovative one-way wave equation developed by Godin [57]. This equation was generalized by Godin to include the source terms and also to account for motion of the medium. The solutions of the differential OWWE are strictly energy conserving and reciprocal. The derivation presented for the multiterm Padé $\mathrm{PE}$ model is applicable to a broad class of finite-difference PE models, ( $p$ ) RAMGEO is a version of RAM modified to handle sediment layers that are range dependent and parallel to the bathymetry [58], (q) RMPE is a ray-mode parabolic-equation solution that is expressed in terms of normal modes in the vertical direction and mode coefficients in the horizontal direction. The model is based on the beamdisplacement ray-mode (BDRM) theory and the parabolic equation (PE) method. The BDRM theory is used to analyze the local normal modes. The PE method is used to solve the wave equations for mode coefficients [59], and (r) 3DWAPE incorporates higher-order finite-difference schemes to handle the azimuthal derivative term in a three-dimensional (3D) parabolic equation model [60]. Broadband pulse propagation problems were solved in a $3 \mathrm{D}$ waveguide using a Fourier synthesis of frequency-domain solutions (3DWAPE) in a penetrable wedge-shaped waveguide [61]. The 3DWAPE model includes a wide-angle paraxial approximation for the azimuthal component. This version of 3DWAPE was used to investigate broadband sound pulse propagation in two shallow-water waveguides: the 3D ASA benchmark wedge and the 3D Gaussian canyon [62].

The specific utility of these categories is further explained below. In applying ocean-acoustic propagation models, the analyst is normally faced with a decision matrix involving water depth (deep versus shallow), frequency (high versus low), and range-dependence (range-independent versus range-dependent ocean environments). The following assumptions and conditions were imposed in construction of Figure 3, which was originally adapted from F. B. Jensen (see [23]).

(1) Shallow water includes those water depths for which the sound can be expected to interact significantly with the sea floor. Typically, a maximum depth of $200 \mathrm{~m}$ is used to delimit shallow water regions. A more accurate definition of shallow water would be expressed in terms of water depth and acoustic wavelength [23].

(2) The threshold frequency of $500 \mathrm{~Hz}$ is somewhat arbitrary, but it does reflect the fact that above $500 \mathrm{~Hz}$, many wave-theoretical models become computationally intensive. Also, below $500 \mathrm{~Hz}$, the physics of some ray-theoretical models may become questionable due to restrictive assumptions.

(3) A solid circle indicates that the modeling approach is both applicable (physically) and practical (computationally). Distinctions based on speed of execution may change as progress is made in computational capabilities. A partial circle indicates that the modeling approach has some limitations in accuracy or in speed of execution. An open circle indicates that the modeling approach is neither applicable nor practical. 


\begin{tabular}{|c|c|c|c|c|c|c|c|c|}
\hline \multirow{4}{*}{ Model type } & \multicolumn{8}{|c|}{ Applications } \\
\hline & \multicolumn{4}{|c|}{ Shallow water } & \multicolumn{4}{|c|}{ Deep water } \\
\hline & \multicolumn{2}{|c|}{ Low frequency } & \multicolumn{2}{|c|}{ High frequency } & \multicolumn{2}{|c|}{ Low frequency } & \multicolumn{2}{|c|}{ High frequency } \\
\hline & RI & $\mathrm{RD}$ & RI & $\mathrm{RD}$ & RI & $\mathrm{RD}$ & RI & $\mathrm{RD}$ \\
\hline Ray theory & & & & & & & & \\
\hline Normal mode & & & & & & & & \\
\hline Multipath expansio & & & & & & & & \\
\hline Fast field & & & & & & & & \\
\hline Parabolic equation & & & & & & & & \\
\hline
\end{tabular}

\footnotetext{
Modeling approach is both applicable (physically) and practical (computationally)

(1) Limitations in accuracy or in speed of execution

Neither applicable or practical
}

FIgURE 3: Domains of applicability of underwater acoustic propagation models.

To provide compact summaries, propagation models are arranged in categories reflecting the basic modeling technique employed (i.e., the five canonical approaches) as well as the ability of the model to handle environmental range dependence (Figure 3). Such factors define what is termed domains of applicability. Hybrid models occasionally compromise strict categorization, and some arbitrariness has been allowed in this classification process. The environmental range dependence considers variations in sound speed or bathymetry. Other parameters may be considered to be range dependent by some of the models, although they are not explicitly treated in this paper.

Figure 3 has been modified in two important respects relative to previous versions [23]. Specifically, a rangedependent capability has been added to the multipathexpansion and to the fast-field (or wavenumber integration) approaches. This change is warranted by the substantial progress made by modelers over the past several years.

Taken together, Figure 3 and Table 1 provide a useful mechanism for selecting a subset of candidate models once some preliminary information is available concerning the intended applications. Note that range-dependent models can also be used for range-independent environments by inserting a single environmental description to represent the entire horizontal range.

3.2.2. Noise Models. Noise is the prevailing, unwanted background of sound at a particular location in the ocean at a particular time. The local noise field is thus characterized by temporal, spatial, and spectral variabilities. The noise generated by natural or anthropogenic point sources is diminished through the effects of propagation to the sonar receiver.

Noise models can be segregated into two categories: ambient-noise models and beam-noise statistics models, as illustrated in Box 1. Ambient-noise models are applicable over a broad range of frequencies and consider noise originating from surface weather, biologics, shipping, and other commercial activities [63]. Beam-noise statistics models [64] predict the properties of low-frequency shipping noise using either analytic (deductive) or simulation (inductive) methods. Table 2 provides a summary of noise models. Superscript letters identify those models that have been added to the inventory since 2003. These letters refer to a brief summary and appropriate documentation. Model documentation can range from informal programming commentaries to journal articles to detailed technical reports containing a listing of the actual computer code. Corresponding information on the legacy models is provided in the 2003 baseline [23] and is not repeated here.

In Table 2: (Noise models), (a) ARAMIS consists of a number of FORTRAN, C++ and MATLAB codes that integrate US Navy standard databases with user-provided sonar system parameters to assess the performance of passive spatial processors [65], (b) DANM is the successor to ANDES. DANM predicts the azimuthal dependence of noise in the $25-5,000 \mathrm{~Hz}$ band [18]. The dynamic ambient noise model (DANM) provides a realistic simulation of the temporal noise field in which a passive receive array operates. The total noise field is obtained by separately calculating wind and shipping noise. The temporal variability of the noise field is simulated by moving merchant ships along major shipping lanes. Shipping databases provide seasonal information about shipping lanes between the world's major ports, as well as the type and number of ships that move in the lanes, (c) ISAAC uses a Gaussian ray-tracing approach to determine the acoustic ray paths between source and target, including those reflected from the sea surface and sea bed. The ray paths may refract with changes in bathymetry, water density, salinity, temperature, and sea-bed type. ISAAC 
Ambient noise

Given: the directional noise intensity per unit solid angle $\left[N_{s}(\theta, \phi)\right]$.

(i) The horizontal noise directionality $[N(\phi)]$ is calculated from $\left[N_{s}(\theta, \phi)\right]$ as: $N(\phi)=\int_{-\pi / 2}^{\pi / 2} N_{s}(\theta, \phi) \cos \theta d \theta$.

(ii) The vertical noise directionality $[N(\theta)]$ is calculated from $\left[N_{s}(\theta, \phi)\right]$ as: $N(\theta)=(1 / 2 \pi) \int_{0}^{2 \pi} N_{s}(\theta, \phi) d \phi$.

(iii) The omnidirectional noise level $(N)$ is then calculated as: $N=\int_{0}^{2 \pi} \int_{-\pi / 2}^{\pi / 2} N_{s}(\theta, \phi) \cos \theta d \theta d \phi$,

or $N=\int_{0}^{2 \pi} N(\phi) d \phi$.

(iv) The horizontal angle $(\phi)$ is measured positive clockwise from true North while the vertical angle $(\theta)$ is measured positive upward from the horizontal plane. No receiver beam patterns were convolved with the noise levels $N(\theta)$ and $N(\phi)$.

Beam-noise statistics

The averaged noise power at the beamformer output $(Y)$ can be expressed as: $Y=\sum_{i=1}^{m} \sum_{j=1}^{n} \sum_{k=1}^{A_{i j}} S_{i j k} Z_{i j k} B_{i j k}$

where $m$ : number of routes in the basin; $n$ : number of ship types; $A_{i j}$ : number of ships of type $j$ on route $i$ (a random variable); $S_{i j k}$ : source intensity of the $k$ th ship of type $j$ on route $i$ (a random variable that is statistically independent of the source intensity of any other ship); $Z_{i j k}$ : intensity transmission ratio from ship $i j k$ to the receiving point; $B_{i j k}$ : gain for a plane wave arriving at the array from ship $i j k$

Box 1: Organization of underwater acoustic noise models into two categories.

TABLE 2: Summary of underwater acoustic noise models. Superscript letters identify those models that have been added to the inventory since 2003 .

\begin{tabular}{|c|c|}
\hline Ambient noise & Beam-noise statistics \\
\hline ANDES & Analytic \\
\hline AMBENT & BBN shipping noise \\
\hline ARAMIS $^{\mathrm{a}}$ & BTL \\
\hline CANARY & Sonobuoy noise \\
\hline CNOISE & USI Array noise \\
\hline \multicolumn{2}{|l|}{ DANES } \\
\hline DANM $^{\mathrm{b}}$ & Simulation \\
\hline DINAMO & BEAMPL \\
\hline DUNES & DSBN \\
\hline FANM & NABTAM \\
\hline ISAAC $^{\mathrm{c}}$ & SIAM-I/II ${ }^{\mathrm{e}}$ \\
\hline \multicolumn{2}{|l|}{ MONM $^{\mathrm{d}}$} \\
\hline \multicolumn{2}{|c|}{ Normal mode ambient noise } \\
\hline RANDI-I/II/III & \\
\hline
\end{tabular}

allows sensitive marine areas such as marine mammal locations, migratory routes and fisheries to be displayed in the GIS alongside acoustic propagation results. Noise impacts on individual species can be assessed by comparing the sound pressure levels generated from anthropogenic activities with sensitivity thresholds to perform environmental risk assessments. The system has been configured specifically for use by offshore industries, environmental agencies, regulators and others to help assess the environmental impact of underwater noise. The $d B h t$ (species) approach provides a measurement of sound that accounts for interspecies differences in hearing ability by passing the sound through a filter which mimics the hearing ability of the species. (The $d B h t$ (species) metric is a pan-specific metric incorporating the concept of "loudness" by using a frequency-weighted curve based on the species' hearing threshold as the reference unit for a $\mathrm{dB}$ scale. A large number of both field and controlled-laboratory measurements have been made of the avoidance of a range of idealized noises, using fish with greatly different hearing as a model. All data, irrespective of source or species, indicate a dependence of avoidance reaction on the $\mathrm{dBht}$ (species) level. The data indicate three regions: no reaction below $0 \mathrm{dBht}$ (i.e., below the species' threshold of hearing), a cognitive avoidance region where increasing numbers of individuals will avoid the noise from 0 to $90 \mathrm{dBht}$, and instinctive reaction at and above $90 \mathrm{dBht}$ where all animals will avoid the noise. This probabilistic model allows the behavioral impact of any noise source to be estimated [66].) This approach provides an indication of the noise level that will be received for the species at various distances from the noise source. These values can then be compared to published data to indicate distances at which a species will demonstrate a strong avoidance reaction, a temporary elevation of hearing threshold or a permanent elevation of hearing threshold [67], (d) MONM (marine operations noise model) incorporates a range-dependent, split-step parabolic equation acoustic model including a shear-wave computation capability. MONM has been used for precise estimation of noise produced by subsea construction noise, marine facilities operation, and seismic exploration, particularly in complex coastal regions. The core algorithm in MONM computes frequency-dependent acoustic transmission loss parameters along fans of radial tracks originating from each point in a specified set of source positions. The modeling is performed in individual one-third octave spectral bands 
covering frequencies from $10 \mathrm{~Hz}$ to several $\mathrm{kHz}$, which covers the overlap between the auditory frequency range of marine mammals and the spectral region in which sound propagates significantly beyond the immediate vicinity of the source. The MONM software makes use of geo-referenced databases to automatically retrieve the bathymetry and acousticenvironmental parameters along each propagation traverse, and incorporates a tessellation algorithm that increases the angular density of modeling segments at greater ranges from a source to provide more computationally efficient coverage of the area of interest. The grid of transmissionloss values produced by the model for each source location is used to attenuate the spectral acoustic output levels of the corresponding noise source to generate absolute received sound levels at each grid point. These are then summed across frequencies to provide broadband levels. A further step of Cartesian resampling and summing of the received noise levels from all the sources in a modeling scenario yields the aggregate noise level for the entire operation on a regular grid from which contours can be drawn on a GIS map. The model can either generate contours at evenly spaced levels or draw boundaries representing biologically significant threshold levels [68], and (e) SIAM II (S.C. Wales, unpublished manuscript) was designed to provide many replications of surface-ship noise for horizontal array systems, particularly narrow-beam systems, but could also be used for omnidirectional systems. Its predecessor, SIAM I $[69,70]$, predicted ship-generated noise over the band 20$120 \mathrm{~Hz}$ by generating many replications so that ensemble statistics could be examined. A review report provides more details on SIAM (I/II) in addition to other legacy beamnoise statistics models [71]. Plotting packages for SIAM were described elsewhere [72].

3.2.3. Reverberation Models. Reverberation is sound that is scattered by the ocean boundaries (sea surface and sea floor) or by the volumetric inhomogeneities. Reverberation is produced by the sonar itself; therefore, the spectral characteristics are essentially the same as the transmitted sonar signal. The intensity of reverberation varies with the range of the scatterers (due to propagation loss) and also with the intensity of the transmitted signal.

Most traditional active sonars are configured in what is termed a monostatic geometry, meaning that the source and receiver are at the same position. In some sonar systems, however, the source and receiver are separated in range or depth, or both, in what is termed a bistatic configuration. Bistatic geometries are characterized by a triangle of source, target and receiver positions, and by their respective velocities. Such geometries are commonly employed in sonobuoy applications and also in active surveillance applications. Geometries involving multiple sources and receivers are termed multistatic.

Reverberation models can be categorized according to cell-scattering or point-scattering techniques (Box 2). Cellscattering formulations divide the ocean into cells, where each cell contains a large number of uniformly distributed scatterers [73]. Point-scattering formulations assume a random distribution of (point) scatterers. Table 3 provides a summary of stand-alone reverberation models. Superscript letters identify those models that have been added to the inventory since 2003. These letters refer to a brief summary and appropriate documentation. Model documentation can range from informal programming commentaries to journal articles to detailed technical reports containing a listing of the actual computer code. Corresponding information on the legacy models is provided in the 2003 baseline [23] and is not repeated here.

In Table 3: (Reverberation models), (a) C-SNAP-REV computes reverberation using the C-SNAP range-dependent normal-mode model. Range dependence of the environment is treated as a one-way coupled-mode solution. Surface and bottom reverberation is obtained by integrating the received intensity over the area insonified by the emitted pulse and that contributes to the reverberation at a given time. An average sound speed is assumed for all the paths (i.e., no group-velocity dependence). The scattering is described by a mode-coupling matrix that is equivalent to the plane-wave scattering function evaluated at discrete angles corresponding to the modes. The incident and scattered mode angles are modified to take into account the local slope and are given by the local phase velocity and the sound speed at the interface. Coherent summation of mode contributions is used to correctly model the effects of deepwater convergent zones. The empirical scattering function is based on Lambert's rule. The model deals mainly with the monostatic case, though the technique is extendable to bistatic geometries. (Unpublished notes by Ellis, SACLANT Undersea Research Centre, La Spezia, Italy, various dates.) (b) HYREV is a high-frequency, monostatic reverberation model suitable for shallow-water environments. Arrival times and transmission losses from the source to scatterers are obtained from the appropriate eigenrays. The compositeroughness theory is used to predict the boundary scattering [74], (c) NOGRP first runs the normal-mode program POPP (a variant of PROLOS), which calls the normal mode subprogram MODES and writes out a binary file of mode information that is then read by the monostatic reverberation code. ROSELLA, an extension of NOGRP, is used to execute the reverberation calculations with beam patterns $[75,76]$, (d) PAREQ-REV is a range-dependent wave-theory model based on the parabolic approximation of the wave equation. The numerical method uses the split-step Fourier marching solution with automatic interpolation of environmental data with range. The code allows a choice of either the standard Tappert-Hardin parabolic equation or the wide-angle equation of Thomson-Chapman. Several choices of starting fields are provided, including a Gaussian source beam of varying width and tilt with respect to the horizontal. Reverberation from the ocean boundaries is computed using standard scattering laws: Lambert's rule for bottom backscatter, and either Chapman-Harris curves or Lambert's rule for sea-surface backscatter. The computational scheme uses reciprocity of propagation to compute the reverberation field for arbitrary receiver depths at the source range. (Unpublished notes by Schneider, SACLANT Undersea Research Centre, 
Cell scattering:

Cell-scattering models assume:

(1) a homogeneous distribution of scatterers throughout the area or volume producing reverberation at any given time;

(2) a sufficiently high density of scatterers to ensure that a large number of scatterers occurs in an elemental volume $(d V)$

or area $(d A)$ at range $r$.

The projector beam pattern is denoted by $b(\theta, \phi)$ and the axial intensity at unit distance is $I_{0}$.

The receiver beam pattern is denoted by $b^{\prime}(\theta, \phi)$ and $s_{v}$ is the ratio of the intensity of the scattering produced by

a unit volume at a distance of $1 \mathrm{~m}$ from the volume to the intensity of the incident sound wave.

The equivalent plane-wave volume reverberation level $\left(\mathrm{RL}_{v}\right)$ is

$$
\mathrm{RL}_{v}=10 \log _{10}\left[\left(I_{0} / r^{4}\right) s_{v} \int_{v} b(\theta, \phi) b^{\prime}(\theta, \phi) d V\right] .
$$

The plane-wave level of boundary reverberation is

$$
\mathrm{RL}_{b}=10 \log _{10}\left[\left(I_{0} / r^{4}\right) s_{b} \int b(\theta, \phi) b^{\prime}(\theta, \phi) d A\right] .
$$

Point scattering:

Point-scattering models are based on a statistical approach that assumes the scatterers are randomly distributed

throughout the ocean. The echoes from each individual scatterer are then summed to compute the reverberation level.

Box 2: Organization of underwater acoustic reverberation models into two categories.

La Spezia, Italy, various dates.), (e) PERM-2D computes backscatter from range-dependent bathymetry in the oceanic waveguide [77]. This technique extends the approach of Collins and Evans [78] to problems involving small-scale and large-scale boundary roughness. The PERM-2D model subdivides the oceanic waveguide into range-independent regions and applies the single-scattering approximation (i.e., multiple forward and backward coupling in the scattered fields is neglected) to formulate a scattering problem for the reflected and transmitted pressure field at each range step. Forward-scattering loss, which can be significant at long ranges and very rough surfaces, is included in the solution. Wide-angle operators, which are accurate for the propagating and evanescent spectrum, are applied to yield stable and convergent iteration formulas for the reflected and transmitted fields [79]. Unlike perturbative methods that are restricted to small-roughness amplitudes, the PERM-2D model is valid for arbitrary roughness subject to the singlescattering approximation, (f) REVPA is a parabolic-equation reverberation model intended for shallow-water applications [80], (g) R-SNAP is a coherent monostatic reverberation model employing the range-dependent propagation model SNAP [81, 82], (h) ARTEMIS (adiabatic reverberation and target echo mode incoherent sum) is a general-purpose numerical model of bistatic target echo level and surface and bottom reverberation for bistatic arrangements in an arbitrary range-dependent environment with arbitrary sound-speed variation [83]. The model minimizes computation time while retaining a reasonably accurate power envelope. The approach is based on the adiabatic normalmode approximation, but with the modal series treated as a continuum and with WKB mode amplitudes (excluding the oscillatory modulation). Outputs are three-dimensional and they can be presented in map form as target echo, reverberation or signal-to-reverberation ratio. Given sparse environmental data, the tradeoff between accuracy and speed is negotiated by intelligent interpolation. This is done by constructing quantities (functions of the desired variables, such as cycle distance, ray angles, etc.) that are more or less linear in space or in mode number. These are converted back to the original variables after linear interpolation, (i) BISTAR is a bistatic, range-dependent reverberation model based on the method of coupled normal modes. The environment is discretized into range-independent segments and the outward propagating field is coupled at the interfaces under the single-scatter hypothesis. The propagation theory and implementation are those of C-SNAP. In order to implement the reverberation prediction, the CW field estimate of C-SNAP has been augmented with a narrowband time-series estimator. The time-domain estimates for the range-dependent environment are available separately and are also used to obtain the reverberation estimates. The scattering process itself can be modeled either as a parametric scattering strength such as Lambert's law or via perturbation theory. The model includes coherent propagation to and from the scattering patch [84-87]. (Also, unpublished notes by K.D. LePage, SACLANT Undersea Research Centre, La Spezia, Italy, various dates.), (j) MURAL, the multistatic reverberation algorithm, supports trainer development, and can be used with any propagation model that produces range-sampled grids of transmission loss, travel time, launch and grazing angles. MURAL contains functions that calculate propagation, scattering and beam patterns. The operation of MURAL couples the algorithm controls to the requested resolution of the prediction with the goal of self-optimizing its performance for the requested resolution [88], (k) SSCARAB is a range-independent raytracing model for calculating both forward propagating and reverberant acoustic fields. Features include improved algorithms to calculate the coherent forward propagating field, the inclusion of upward refracting rays in the sediment, definition of bistatic sourcereceiver geometries, and the possibility of specifying $3 \mathrm{D}$ beam patterns of the source and receivers. The forward and back propagating acoustic fields are calculated by tracing rays both in the water column and sediment. Only contributions from the ocean bottom are considered in calculation of the reverberation. The local scattering properties of the seabed are described by known power-law expressions for both the interfaces of stratified sediment layers and volume inhomogeneities in the sediment. These scattering kernels 
TABLE 3: Summary of underwater acoustic reverberation models. Superscript letters identify those models that have been added to the inventory since 2003.

\begin{tabular}{|c|c|}
\hline \multicolumn{2}{|c|}{ Cell scattering } \\
\hline Monostatic & Bistatic/multistatic \\
\hline C-SNAP-REV & ARTEMIS $^{h}$ \\
\hline DOP & BAM \\
\hline EIGEN/REVERB & $\mathrm{BiKR}$ \\
\hline HYREV $^{\mathrm{b}}$ & BiRASP \\
\hline MAM & BISAPP \\
\hline NOGRP/ROSELLA ${ }^{c}$ & BISSM \\
\hline PAREQ-REV ${ }^{\mathrm{d}}$ & BISTAR $^{\mathrm{i}}$ \\
\hline PEREV & MURAL $^{j}$ \\
\hline PERM-2D ${ }^{\mathrm{e}}$ & OGOPOGO \\
\hline REVMOD & RASP \\
\hline REVPA $^{\mathrm{f}}$ & RUMBLE \\
\hline REVSIM & S-SCARAB ${ }^{k}$ \\
\hline R-SNAPg & \\
\hline TENAR & \\
\hline \multicolumn{2}{|c|}{ Point scattering } \\
\hline Monostatic & Bistatic/multistatic \\
\hline REVGEN & BORIS-SSA $^{\mathrm{m}}$ \\
\hline RITSHPA $^{1}$ & $\begin{array}{c}\text { Under-ice reverberation } \\
\text { Simulation }\end{array}$ \\
\hline
\end{tabular}

are dependent on physical descriptors of the bottom such as seabed roughness. S-SCARAB is computationally efficient compared to other reverberation tools based on normalmode or parabolic equation approaches, particularly at higher frequencies [89], (1) RITSHPA is a reverberation module intended for use in high-resolution, wideband sonar simulators [90] in which reverberation is stochastic (non-Rayleigh) and follows the K-distribution [91]. Hybrid multipaths, in which the return path is different from the transmit path, are also considered. RITSHPA assumes spherical propagation loss (i.e., isovelocity water column) and uses widely known formulas to compute reflection and scattering at boundaries, and (m) BORIS-SSA (bottom reverberation from inhomogeneities and surfaces small-slope approximation) simulates time series resulting from acoustic scattering off various seafloor types involving various sourcereceiver geometries [92-96]. This package is an upgrade of BORIS-3D. The model parameters characterize the sonar directivity and pulse shape, the geometrical configuration of the scattering problem and the geophysical characteristics of the seafloor, the sea surface, or other surfaces. These surfaces can have various statistical behaviors or can be obtained from deterministic data based on measured surface heights.

3.2.4. Sonar Performance Models. Sonar performance models combine environmental models, propagation models, noise models, reverberation models, and appropriate signalprocessing models to solve the sonar equations. A further segregation can be made according to source/receiver geometry into monostatic and bistatic categories (Box 3). The monostatic formulation of the sonar equations follows a traditional format [73], while the bistatic formulation is adapted from H. Cox (see [23]). The performance of passive sonars (i.e., those that detect sound emitted from a target of interest) could be modeled using the appropriate environmental descriptors together with suitable propagation-loss and noise models. The performance of active sonars (i.e., those that transmit an interrogation signal and then detect the echo returned from a target of interest) could be modeled similarly with the addition of suitable reverberation models.

Sonar performance models can be further categorized as active sonar models, model operating systems and tactical decision aids. Model-operating systems provide a framework for the direct linkage of data-management software with computer-implemented codes of acoustic models, thus facilitating the construction of versatile simulation capabilities. Model-operating systems are further distinguished from stand-alone active sonar performance models by virtue of their ability to conduct sensitivity analyses by computing components of the active-sonar equation using alternative solution techniques. Since sonar model operating systems normally utilize existing ocean-acoustic models and standard oceanographic databases, these systems are unique only in the sense of the number and types of models and databases included, and the particular architectures, graphical user interfaces (GUIs), and other features employed. Tactical decision aids represent a form of engagement-level simulation that blends environmental information with tactical rules. These decision aids guide system operators and scene commanders in planning missions and allocating resources by exploiting knowledge of the operating environment. Table 4 provides a summary of sonar performance models. Superscript letters identify those models that have been added to the inventory since 2003. These letters refer to a brief summary and appropriate documentation. Model documentation can range from informal programming commentaries to journal articles to detailed technical reports containing a listing of the actual computer code. Corresponding information on the legacy models is provided in the 2003 baseline [23] and is not repeated here.

In Table 4: (Sonar performance models), (a) ESPRESSO is a minehunting sonar performance assessment tool developed as a NATO standard for interfacing with NATO planning and evaluation tactical decision aids [97]. It uses BELLHOP as a propagation submodel, which has also been modified to calculate beam-based, high-frequency reverberation [98]. Espresso exists in two versions: one intended for scientific use and the other for military use. The scientific version of Espresso provides greater flexibility than the military version, including the ability to select sub-models and view the results of any sub-model. A user guide addresses the user interface for Espresso and describes the underlying software models and data output options available within Espresso [99]. There is a separate user guide for the military version, Espresso $(\mathrm{m})$, which provides greater tailoring of the user interface, including the ability to customize parameters [100]; (b) LYBIN is a range-dependent, raytheoretical model developed by Svein Mjølsnes of the Norwegian Defence Logistic Organization [101-103]. Rangedependent environmental inputs include bottom type and topography, volume backscatter, sound speed, temperature, salinity, wind speed, and wave height. Choices of 
Active sonar equations (monostatic)

(i) Noise background

$$
\mathrm{SL}-2 \mathrm{TL}+\mathrm{TS}=\mathrm{NL}-\mathrm{DI}+\mathrm{RD}_{N} .
$$

(ii) Reverberation background

$$
\mathrm{SL}-2 \mathrm{TL}+\mathrm{TS}=\mathrm{RL}+\mathrm{RD}_{R} .
$$

Passive sonar equation

$$
\mathrm{SL}-\mathrm{TL}=\mathrm{NL}-\mathrm{DI}+\mathrm{RD} .
$$

SL: source level; TL: transmission loss; TS: target strength; NL: noise level; DI: receiving directivity index;

RL: reverberation level; RD: recognition differential.

Active sonar equations (bistatic)

The signal excess (SE) can be represented as:

(i) $\mathrm{SE}=\mathrm{ESL}-\mathrm{TL}_{1}-\mathrm{TL}_{2}-\left[\left(N_{0}-\mathrm{AG}_{N}\right) \oplus R_{0}\right]+\mathrm{TS}-\Lambda-L$,

the energy source level (ESL) is related to the intensity source level (SL) as:

(ii) $\mathrm{ESL}=\mathrm{SL}+10 \log _{10} T$

where $T$ is the duration of the transmitted pulse,

The echo energy level (EEL) received from the target at a hydrophone on the receiver array is then:

(iii) $\mathrm{EEL}=\mathrm{ESL}-\mathrm{TL}_{1}-\mathrm{TL}_{2}+\mathrm{TS}$,

where TS is the target strength, $N_{0}$ is the noise spectral level, $R_{0}$ represents the reverberation spectral level, $\mathrm{AG}_{N}$ is the array

gain against noise, $\Lambda$ is the threshold on the signal-to-noise ratio (SNR) required for detection,

$L$ is a loss term to account for time spreading and system losses,

$\bigoplus$ represents power summation, $\mathrm{TL}_{1}$ is the transmission loss from source $(S)$ to target $(T)$,

and $\mathrm{TL}_{2}$ is the transmission loss from target $(T)$ to receiver $(R)$.

Box 3: Sonar performance models are based upon the sonar equations, which are the basic building blocks for both monostatic and bistatic sonar geometries.

calculation outputs include ray trace, transmission loss, reverberation (surface, volume, and bottom), noise, signal excess, probability of detection, travel time, and impulse response. The transmission-loss module was evaluated by NURC [104]. LYBIN is available commercially from the Forsvarets forskningsinstitutt (FFI), (c) MOC3D [105] is a 3D model developed from the 2D model MOCASSIN [106]. MOC3D was used to investigate the importance of outof-plane sound propagation in a shallow-water experiment in the Florida Straits [107], (d) MODRAY was developed in conjunction with DSTO (Australia) to simulate the propagation of sound through the underwater environment $[108,109]$. MODRAY uses classical ray-tracing theory to produce sound-pressure time series at one or more receivers. The marine environment is range-independent. Seafloor composition can be specified, the sound-speed profile can be arbitrary, noise includes wind, rain, biological and shipping sources, and scattering by marine organisms is included. MODRAY can model an arbitrary number of sound sources, reflectors and receivers stationed on moving platforms. MODRAY has been used extensively to model the effectiveness of underwater communications algorithms
$[110,111]$, (e) SUPREMO is a multistatic sonar performance model that includes propagation, target echoes, reverberation and noise, all plotted as a function of delay time and bearing using an equivalent map projection. A modular propagation section makes it possible to separate the effects of propagation modeling (e.g., theoretical basis and rangedependence) from those of scattering computations (e.g., computational efficiency, bottom slope and scattering law). Special attention is paid to problems of interference from multiple sources firing in sequence, target aspect dependence from multiple receivers, mixed FM and CW, mismatched source and receivers, multiple displays (one for each bistatic pair), and presentation of results [82, 112-115]. Predictions of acoustic reverberation and target echo intensity made by the SUPREMO sonar performance model were compared with measured data gathered in the Malta Plateau region of the Mediterranean Sea. The observed model-measurement agreement demonstrated the suitability of SUPREMO for use with an environmentally adaptive, low-frequency, active sonar system [116]. Version 2.0 of SUPREMO has been documented [117, 118], (f) SWAMI models range-andazimuth dependence $(\mathrm{N} \times 2 \mathrm{D})$ via adiabatic modes [119]. 
TABle 4: Summary of sonar performance models. Superscript letters identify those models that have been added to the inventory since 2003.

\begin{tabular}{|c|c|c|}
\hline \multicolumn{3}{|c|}{ Active sonar models } \\
\hline Active RAYMODE & & MINERAY \\
\hline ALMOST & & MOCASSIN \\
\hline ASPM & & $\mathrm{MOC} \mathrm{D}^{\mathrm{c}}$ \\
\hline CASTAR & & MODRAY $^{\mathrm{d}}$ \\
\hline CONGRATS & & MSASM \\
\hline ESPRESSO $^{\mathrm{a}}$ & & NISSM-II \\
\hline GASS & & SEARAY \\
\hline HODGSON & & SONAR \\
\hline INSIGHT & & SST \\
\hline INSTANT & & SUPREMO \\
\hline LIRA & & SWAMI/DMOS ${ }^{f}$ \\
\hline LORA & & SWAT \\
\hline LYBIN $^{\mathrm{b}}$ & & UAIM $^{\mathrm{g}}$ \\
\hline \multicolumn{3}{|c|}{ Model operating systems } \\
\hline CAAM & GSM - Bistatic & \\
\hline CALYPSO $^{\text {h }}$ & HydroCAM & \\
\hline CASS & PRISM & \\
\hline ESME/NEMO ${ }^{\mathrm{i}}$ & SPPS & \\
\hline \multicolumn{3}{|c|}{ Tactical decision aids } \\
\hline \multicolumn{3}{|l|}{ ASPECT SPPSk } \\
\hline \multicolumn{3}{|l|}{ IMAT } \\
\hline NECTA & & \\
\hline
\end{tabular}

SWAMI has been used to support the towed integrated active-passive sonar (TIAPS), which was developed as a technology demonstrator for the Canadian Forces. Software development utilized a system test bed (STB) comprising a collection of scaleable, portable, and reusable components for constructing sensor-based applications. The toolset contains modules to produce predictions of transmission loss, reverberation (MONOGO), signal excess, and probability of detection. SWAMI includes the capability to model various source and receiver configurations including omnidirectional arrays, line-arrays (both horizontal and vertical) and volumetric arrays [120]. DMOS (DRDC Atlantic Model Operating System) is an evolution of the SWAMI suite of programs that enables a user to model transmission loss, reverberation, signal excess, and probability of detection for active sonars [121]. Originally, the suite was based on normal-mode theory (PMODES); however, normalmode theory is best suited to shallow water and low acoustic frequencies, and users occasionally need to model reverberation and other parameters under other conditions. DMOS was enhanced to include a Gaussian-beam acoustic propagation model, BELLHOP, as an alternate propagation engine. A DRDC-extended version that included a rangedependent capability was chosen. DMOS may now be used to model both active and passive sonars in shallow or deep water; (g) UAIM is a system of computer algorithms designed to predict multibeam sonar performance and image the effects of variations in bathymetry, clutter objects, and bottom type, particularly in complex shallow-water environments [122]. The model addresses perceived weaknesses in existing mine-countermeasure (MCM) sonar performance models. The propagation code in UAIM was derived from RASP while the reverberation and signal excess codes were derived from GSM. Modifications were made to these codes to accommodate high-frequency range-dependent applications. A utility package called SoundGuide assists the operator in creating the large input file, executes UAIM and plots the resulting data, (h) CALYPPSO (KA $\Upsilon \Upsilon \Psi \Omega$ ) is an integrated computer environment that was developed for the analysis of underwater acoustic detection systems [123]. The communication language is Greek. It can treat passive detection, broadband, or LOFAR, as well as active detection, monostatic or multistatic. The system contains compact databases for environmental (coastline, bathymetry, oceanographic, geological) and operational (system parameters, target characteristics) data. Acoustic propagation calculations are performed using normal-mode, parabolic approximation, and ray-theoretical codes supporting broadband calculations in range-dependent environments. The results include transmission loss, reverberation levels, detection thresholds and probabilities of detection for a variety of userdefined operational scenarios. (This work was supported by the Greek MOD.) (i) ESME (effects of sound on the marine environment) is a multidisciplinary research and development effort to explore the interactions between anthropogenic sounds, the acoustic environment and marine mammals [124, 125]. The "ESME workbench" models the entire sound path including the sound sources (impulsive or explosive), the medium (water column and seafloor), and the temporary threshold shift (TTS) models of the marine mammals. (TTS refers to a temporary increase in the threshold of hearing, i.e., the minimum intensity needed to hear a sound at a specific frequency, but which returns to its preexposure level over time.) The goal is to predict impacts of anthropogenic sounds on marine mammals. This entails three elements: (1) accurate estimates of the sound field in the ocean; (2) accurate estimates of the cumulative sound exposure of the marine mammals; (3) reliable predictions of the incidence of TTS for the species of interest given the estimated cumulative exposure. The flexibility and computational efficiency of the ESME Workbench will be enhanced by merging the NEMO (NUWC exposure model) and ESME approaches into the "One Navy Model," which is intended to serve as the standard simulation system for use in predicting impacts of anthropogenic sound sources on marine life for environmental compliance purposes, (j) SPPS, the sonar performance prediction system (developed in Germany), evaluates the performance of sonar systems in various navalwarfare scenarios and assists in sonar-system design efforts. The model accommodates active and passive sonar detection problems involving both broadband and narrowband signals using a variety of sonar antennas. The integrated oceanacoustic propagation model spans the frequency range $10 \mathrm{~Hz}$ to $1 \mathrm{MHz}$ by using a hybrid combination of parabolicequation, coupled-mode, and ray propagation submodels. Environmental databases describe the ocean environment, 
targets, platforms and sonar-system characteristics. The reverberation model predicts volume, surface and bottom components. Noise sources include ambient, biological, rain, shipping, ice, seismic exploration, and self-noise [126], and (k) ASPECT, the active system performance estimate computer tool, is a multistatic tactical decision aid (TDA). It computes estimates of system performance for active underwater acoustic sensors. ASPECT was originally designed to satisfy the requirements of mission planning software for the IEER (improved extended echo ranging) system. However, virtually any multistatic or monostatic active acoustic system can be modeled using this software package. ASPECT uses the FAME (fast multipath expansion) model for rangeindependent calculations of transmission loss and ASPM (active system performance model) for range-dependent transmission loss and reverberation. These computations are then fed into MSASM, which is capable of estimating the performance of active sonar systems for multiple sources, receivers, and targets. It simulates target motion including such features as normal and uniform probability distribution, various speed, and course distributions, as well as target evasion modeling to a limited degree. ASPECT version 2.0 (and beyond) supersedes the MSASM Interactive Execution and Optimization System (MINEOS), which was the first version of mission planning software developed for the IEER program. ASPECT also exists as a standalone version [127].

\subsection{Inversion Techniques}

3.3.1. Adjunct Tools for Oceanographers. Inverse acoustic sensing techniques presently constitute adjuncts to direct measurement methods. However, the application of inverse acoustic sensing techniques to dynamical studies of the oceans' boundaries and interior show great promise for three reasons. First, such data can be used to establish comparative baselines for other remote sensors, such as satellites, by providing synoptic portraitures of the interior oceans together with concurrent ground-truth data at the sea surface. Second, inverse acoustic techniques often afford useful insights into a broad class of oceanic phenomena since their successful employment relies heavily on the use of numerical models first to understand the role of the oceans as an acoustic medium. Third, inverse data provide estimates of spatially integrated and temporally averaged oceanic conditions that are not readily available from traditional oceanographic sensors.

Recently, acoustical oceanographers have employed underwater-acoustic models as adjunct tools for inversesensing techniques that can be used to obtain synoptic portraitures of large ocean areas or to monitor long-term variations in the ocean.

Useful information about the ocean can be derived from both forward and inverse applications of underwater sound. Direct (or forward) methods include traditional sonar applications. Inverse methods extract information from direct measurements of the physical properties of the ocean. These inverse methods combine the direct physical measurements with theoretical models of underwater acoustics. The objective is to estimate detailed underwateracoustic fields from sparse physical measurements using the theoretical models as guides. Inversions of controlledsource, noise, and reverberation fields have been performed successfully (Box 4).

Inverse sensing techniques that employ acoustics have been used in several subdisciplines of geophysics including seismology, meteorology, and oceanography. In oceanography, inverse acoustic data provide estimates of spatially integrated and temporally averaged oceanic conditions that are not readily available from a traditional constellation of point sensors. Forward (or direct) models are important in solving inverse problems.

\subsubsection{Propagation (Acoustic Field Measurements). Acoustic} propagation characteristics in the deep oceans are determined largely by the refractive properties of the water column and, to a lesser extent, by the surface and bottom boundary conditions. Propagation measurements can be used to infer bulk properties of the water column such as temperature, sound speed, density, and currents. In shallow-ocean areas, where propagation characteristics can be strongly affected by the bottom boundary, propagation measurements can be used to infer properties of the sea floor such as composition and scattering characteristics. A wide spectrum of inverse problems has been addressed in underwater acoustics including estimation of geoacoustic parameters, acoustic thermometry, and shallow-water characterization. Inverse acoustic sensing methods utilizing the propagation characteristics of the oceans include matched field processing, ocean acoustic tomography and deductive geoacoustic inversion [23]. A new technique known as a time reversal mirror (TRM) uses inverse methods to refocus received signals back to the source.

Range-dependent ray-theoretical models are typically used for deep-water applications involving tomographic experiments as well as for high-frequency experiments in shallow water. Range-dependent wave-theoretical models based on normal-mode, fast-field (wavenumber integration), or parabolic-equation approaches are preferred for low-frequency experiments in shallow water.

3.3.3. Noise. The ambient noise field in the oceans is described by the spectral, spatial, and temporal characteristics of sound generated by both natural and industrial sources. Measurements of these characteristics can provide useful information regarding the nature of the noise sources themselves as well as physical features within the oceans. Examples of inverse applications of the noise field include wind speed determination, rainfall measurements, object imaging (acoustic daylight), and geoacoustic inversion.

3.3.4. Reverberation. The reverberation field in the oceans is the product of acoustic scattering by the surface and bottom boundaries and by inhomogeneities within the oceans. The utility of the reverberation field as an inverse sensing technique is analogous to that of the ambient noise field. For example, the reverberation field can be inverted to 
Propagation

(i) Matched field processing:

(a) source localization,

(b) marine environment characterization.

(ii) Ocean acoustic tomography:

(a) density field (eddies, currents),

(b) temperature (climate monitoring).

(iii) Deductive geoacoustic inversion:

(a) sediment parameters,

(b) sea-floor scattering characteristics.

(iv) Time reversal mirror (TRM):

(a) signal refocusing.

Noise

(i) Field inversion:

(a) wind speeds,

(b) rainfall rates.

(ii) Acoustic daylight:

(a) object imaging.

(iii) Geoacoustic inversion:

(a) seabed acoustics.

Reverberation

(i) Field inversion:

(a) sea-floor imaging.

(ii) TRM nulling:

(a) reverberation attenuation.

Box 4: Summary of inverse ocean acoustic sensing techniques.

image the sea floor. A new development uses time reversal mirror (TRM) methods to attenuate reverberant returns.

\section{Emerging Solutions}

4.1. Background. This section addresses advanced processing methods in addition to novel methods by which to maximize the interpretation, and thus utility, of archival and experimental data.

\subsection{Advanced Integrated Modeling Approaches}

4.2.1. Acoustic Integration Model. The acoustic integration model (AIM) combines a movement simulator with underwater acoustic models to predict (and thus minimize and mitigate) the potential effect of sound on marine mammals [128]. Simulated sound sources and animals are programmed to move in location and depth over time in a realistic fashion. AIM is a Monte Carlo statistical model based on a whale movement and tracking model and an underwater acoustic backscattering model for a moving source. Currently, AIM incorporates the BELLHOP and PE propagation models in addition to the ETOP05 bathymetry and GDEM sound-speed profile databases. The ETOP05 data set is the highest resolution topographic data set with global coverage that is publicly available, with elevations posted every 5 arc minutes (approximately $10 \mathrm{~km}$ ) for all land and sea floor surfaces. ETOP05 is distributed without restriction by the National Oceanic and Atmospheric Administration
(NOAA) through its National Geophysical Data Center (NGDC).

4.2.2. Marine Mammal Movement Models. A method has been developed for modeling marine mammal movement and behavior $(3 \mathrm{MB})$ for use in environmental impact assessments [129]. Estimating the impact of anthropogenic sound on marine animals entails consideration of animal location and behavior at the time of sound exposure. The ESME model (see Table 4) incorporates $3 \mathrm{MB}$ to provide fine-scale control over simulated marine-animal (animat) movement and behavior. Control over the animats is scaleable to the information available regarding the species of concern. Movement and behavior are stochastically determined by sampling from distributions describing rates of movement in the horizontal and vertical planes, direction of travel, time at the surface between dives, time at depth, and time in and transition between behavioral states. Influence of behavior over each of the other distributions is also permitted.

As part of the NATO Undersea Research Centre (NURC) broadband environmentally adaptive concept, the SUPREMO sonar performance model was incorporated within a feedback mechanism for sonar-parameter optimization for any specified ocean environment [130]. The feasibility of using active sonars to monitor the movement of marine mammals was investigated in order to recommend stand-off distances within which an acoustic source should not be deployed [131].

4.2.3. Energy Flux Models. Some applications, such as work relating to acoustic impacts on marine mammals, do not require extremely high-fidelity model outputs. Transmission losses averaged over depth, for example, are often adequate.

An approach referred to as energy-flux models [132] is useful for rapid calculation of transmission loss where the propagation conditions are dominated by numerous boundary-reflected multipaths and when only the coarse characteristics of the acoustic field are needed.

In specific configurations, especially at long ranges in shallow-water environments, the transmitted field can be viewed as being composed of many paths propagating by successive reflections from the surface and bottom boundaries. Here, the acoustic energy will remain trapped between these two boundaries. Furthermore, if the acoustic frequency is high enough that the field oscillations can be considered to be random, then an average intensity can be calculated using simple algebraic formulas [23].

This concept can be extended to ocean environments where the sound speed is not constant, or where there are slight losses at the boundaries. In such cases, the transmitted field cannot be taken as a volumetric average. Rather, it has to be decomposed into its angular components and the cyclic characteristics of the various beams must be detailed [133].

This approach is very useful for predicting incoherent transmission losses in cases where there are a large number of modes $(\geq 6)$. These flux models are fast because there is no requirement to find modes or eigenrays. They can also lead to 
very simple and intuitive expressions. This method has been extended for reverberation [134].

4.2.4. Waveguide Invariant Models. In weakly rangedependent ocean environments, it has been observed that the acoustic wavefield can be described in terms of ray-based or mode-based approaches [135, 136]. Using ray-based descriptions, distributions of the ray amplitude and phase (travel time) are largely controlled by the so-called stability parameter $(\alpha)$. Alternatively, using modebased descriptions in either purely range-independent environments or in range-independent environments upon which weak (range-dependent) perturbations have been superimposed, many wavefield properties are controlled by the so-called waveguide invariant $(\beta)$. When $\beta$ is evaluated using asymptotic mode-theoretical results (in a stratified environment), it was found that $\beta=\alpha$, which is consistent with the well-known ray-mode duality. In weakly rangedependent environments, however, $\alpha$ was found to control ray stability and several measures of travel-time dispersion while $\beta$ controlled the spread of modal-group delays due to mode coupling.

In essence, the waveguide invariant $(\beta)$ summarizes the pattern of constructive and destructive interference between acoustic modes propagating in the ocean waveguide. It manifests itself as interference fringes (or striations) in a plot of frequency versus source-receiver separation. The waveguide invariant summarizes in a single scalar parameter the dispersive propagation characteristics in a waveguide.

\subsection{Advanced Nonintrusive Measurement Approaches}

4.3.1. Acoustic Transmission Options. In acoustic probing, transmit signals can be adapted according to in situ estimates of channel conditions. Waveform characteristics could be set using returns from the previous transmission as an indicator of channel response. Rapidly modifying processing parameters by analyzing previously received signals addresses the problem of fluctuating acoustic channel response owing to variations in environmental factors. Such optimal matching to the estimated channel response would improve targetecho stability [137].

Since sound level, frequency, and duration are critical parameters in causing physical damage to marine life, transmitting over a wider frequency spectrum using spreadspectrum techniques or noise-like signals could avoid tissue damage by reducing the time spent (or energy transmitted) in particular frequency bands. Spread-spectrum techniques use a pseudorandom spreading code to produce a wideband source signature. Signals must possess high range and Doppler resolution and minimize cross-talk between different users.

Noise-like signals emulate ambient noise by covertly adapting to the fluctuating ambient noise field. Designers could model pseudo-random signals based on bioacoustic noise, surf noise (when high-frequency broadband transients should be useful [138]) or shipping noise (when near CW would be more useful).
Advances in sonar technologies have rendered modern sonar systems useful for in situ measurements of the ambient marine environment. For example, through-thesensor measurements of the ocean impulse response have enabled modern sonars to perform collateral functions as tactical environmental processors.

A recent through-the-sensor remote-sensing technique for acoustic-parameter estimation has been referred to as SABLE (sonar active boundary loss estimation) [139]. Bottom scattering strengths were derived from active hull-mounted naval sonar data by using eigenray paths modeled by CASS and GRAB to associate sonar-signal attributes with specific propagation paths.

4.3.2. Collision Avoidance. Cetaceans are prone to collisions with fast-moving vessels. In areas of high cetacean and vessel densities, the sperm whale (Physeter macrocephalus) is of great concern. Sperm whales are highly vocal and can be localized with passive sonar; however, when at or near the surface (i.e., when they are at greatest risk of collision), they tend to stop vocalizing. Techniques employing active sonars have proved to be inefficient due to short detection ranges and high closing speeds. The efficiency of a passive-sonar solution was evaluated that used vocalizing whale clicks (at depth) as acoustic sources to detect silent whales [140]. This solution could serve as a noninvasive complement to a more complex passive localization and collision-avoidance system. A wideband $\mathrm{N} \times 2 \mathrm{D}$ (range-and-azimuth-dependent) ray model was used to simulate a passive solution comprising an arbitrary number of active acoustic sources (vocalizing whales), an illuminated object (silent whale) and a passivesonar receiver, all positioned in three-dimensional space with arbitrary bathymetry. Both curved-line and straight-line ray solutions were implemented, with the latter providing greater computational speeds at the expense of temporal and angular fidelity. The simulation recreated the resultant mixture of direct, reverberated and target-backscattered signals arriving at the receiver for any array configuration, any number of sources and one target. In the vicinity of the Canary Islands, the simulations demonstrated the applicability of the concept with a maximum detection range on the order of $1 \mathrm{~km}$.

\subsection{Advanced Processing Methods}

4.4.1. Adjoint Modeling. The principal application of adjoint models is sensitivity analysis. When quantitative estimates of sensitivity are desired, a mathematical model of the phenomenon or relationship is required. While models have been used to assess the impacts of perturbations and thus estimate sensitivity, a more efficient approach is to use the model's adjoint to determine optimal solutions. The adjoint operates backward in the sense that it determines a gradient with respect to input from a gradient with respect to output. In a temporally continuous model, this would appear as integration backwards in time. If there are no numerical instabilities associated with irreversible processes in the tangent linear model acting forward in time, there will be 
none in the adjoint acting backward in time (a tangent linear model provides a first-order approximation to the evolution of perturbations in a nonlinear forecast trajectory). The greatest limitation to the application of adjoints is that the results are useful only when the linearized approximation is valid. The adjoint operator (matrix transpose) back-projects information from data to the underlying model. Geophysical modeling calculations generally use linear operators that predict data from models. The usual task is to find the inverse of these calculations, that is, to find models (or make maps) from the data. The adjoint operator tolerates imperfections in the data and does not demand that the data provide full information.

The concept of adjoint modeling was introduced in shallow water acoustics for solving inverse problems [141]. In related work, the concept of backpropagation was reviewed in the context of adjoint modeling [142]. The different implementations of this concept were compared and discussed in the framework of experimental acoustic inversion in shallow water with application to source localization, ocean acoustic tomography, geoacoustic inversion and underwater communications. Well-established inversion (or focalization) methods based on matched-field processing, model-based matched filter and time-reversal mirror are related to lesser known techniques such as acoustic retrogation and other variants of backpropagation. In contrast to the latter, adjoint-based variational inversion approaches make use of the adjoint of a forward model to backpropagate the model-data mismatch at the receiver toward the source.

An adjoint model was derived from a forward-propagation model (e.g., normal mode or parabolic equation) to propagate data-model misfits at the observation point back through the medium to the site of those medium perturbations that were not accounted for in the forward model and which gave rise to the observed data-model misfits [143]. This property makes adjoint models attractive for use in acoustic inversion experiments.

4.4.2. Stochastic Resonance. Stochastic resonance refers to a phenomenon that is manifested in nonlinear systems whereby weak signals can be amplified in the presence of noise [144]. Three components are necessary: a threshold, a periodic signal and a source of noise. The response of the system undergoes resonance-like behavior as the noise level is varied [145]. Stochastic resonance was applied to enhance the detection of target signals masked by shallowwater reverberation [146]. Specifically, parameter-induced stochastic resonance was used to tune system parameters to recover the spatial signal that was corrupted by Gaussian noise. This method also has applicability when processing spatial signals that are corrupted by $K$-distributed envelope noise (a standard model for radar clutter).

4.4.3. Optimization Techniques. Ant colony optimization (ACO) has elements in common with genetic algorithms [147]. Both are population-based algorithms that search a discrete space and provide uncertainty analyses. The main difference is the mechanism that handles and recombines components of better candidate solutions (i.e., antpheromones trails versus genetic operators). Ant colony optimization is further distinguished by having a form of memory (the ant pheromone trails), while genetic algorithms are without memory. Specifically, when the pheromones evaporate, identifiers of paths with above-average quality fade out. Thus, high rates of evaporation mean that only recent information can be retrieved (typical for shortterm memory); alternatively, low rates of evaporation allow recollection of much older information (typical for longterm memory). When applied to inversion, the world of the ants acts as an analogy for the geoacoustic environment.

An efficient and reliable method was proposed for performing the inversion of a neural-network underwater acoustic model to obtain sea-floor parameters [148]. Two different versions of a modified particle-swarm optimization were used: two-step gradient approximation and hierarchical cluster-based approximation. Both approaches worked well.

Tabu search has traditionally been applied to combinational optimization problems $[149,150]$. The tabu search begins by marching to a local minimum. This approach avoids entrapment in cycles by forbidding (tabu), or penalizing, moves that take the solution in the next iteration to points in the solution space previously visited.

4.4.4. Chaos. In the presence of weak fluctuations in the sound-speed field, it has been observed that ray trajectories in ocean waveguides exhibit a chaotic behavior in which the travel times along eigenrays form compact clusters, the center of which is close to the arrival time of an unperturbed ray with similar geometry [151]. The deepwater acoustic waveguide was modeled by an unperturbed sound-speed profile $\left[c_{0}(z)\right]$ combined with weak fluctuations of sound speed $[\delta c(r, z)]$ caused by a random field of internal waves conforming to the Garrett-Munk spectrum. Formally, ray equations in a random inhomogeneous medium can be considered as stochastic equations whose parameters are determined by a random function $\delta c$. Such nonlinear equations can be solved in the framework of ordinary perturbation theory, but only for short ranges. Instead, the ray structure was analyzed by using the Hamiltonian formalism in terms of action-angle canonical variables whose variation was small under conditions of weak perturbations. It was estimated that ray arrival times at a distance $r$ occupied an interval whose average width increased in proportion with $r^{1.5}$, in agreement with previous investigators. Moreover, for $r<10^{3} \mathrm{~km}$, the ray trajectories forming the cluster deviated only slightly from the unperturbed ray trajectory and the cluster width grew in proportion with $r^{0.5}$. For $r>10^{3} \mathrm{~km}$, the width of the cluster grew in proportion with $r^{2}$.

Chaotic and stochastic nonlinear ray dynamics can occur in underwater-acoustic waveguides with longitudinal variations in the sound speed caused by internal waves [152]. This situation was investigated using a model of a "frozen" medium in which the temporal variations in the environment were neglected and only the spatial variations due to the comparatively small propagation time of sound 
in the ocean were considered. Coherent ray clusters were observed in which large fans of rays with close initial conditions preserved close current dynamical characteristics over long distances. The cluster structure could be considered to consist of statistical and coherent parts. Rays belonging to the statistical part propagated in the same areas of phase space with the same value of the Lagrangian, but did not correlate with each other and demonstrated exponential sensitivity to initial conditions. Rays belonging to the coherent part did not demonstrate sensitivity to initial conditions. This coherent clusterization might be a useful property for acoustic tomography in terms of determining spatiotemporal variations in the hydrological environment under conditions of ray chaos [153].

\section{Summary}

This paper has reviewed changes in the ocean soundscape, changes that have been driven by both anthropogenic activity and natural factors. New regulatory initiatives have placed additional restrictions on uses of sound in the ocean, and mitigation of marine-mammal endangerment is now an integral consideration in acoustic-system design and operation. Emphasis has been placed on leveraging advanced modeling methods to solve emerging scientific and engineering challenges in this field.

Naval sonars have been redesigned as high-power multistatic systems capable of operating in complex coastal environments against quiet submarines. Littoral training ranges to support this new generation of sonar systems must comply with more stringent environmental regulations. Such compliance is often assessed using advanced modeling techniques coupled with in situ data collection. Oceanographic data collection is supported by underwater networks consisting of sensors and vehicles deployed in concert. These networks employ nodes that communicate via acoustic channels that have low data rates and time-varying fading.

Seismic exploration has ventured into deeper waters in search of diminishing energy resources using source arrays that are powered by high-pressure air. Controlled-exposure experiments have studied changes in the behavior of nearby whales due to these powerful sources; however, modeling uncertainty complicates the regulatory interpretation of average sound-exposure conditions.

Increased merchant shipping activity has had a measureable impact on the ocean soundscape over the past four decades: the average noise has increased by $2.5-3 \mathrm{~dB}$ per decade in the frequency band $30-50 \mathrm{~Hz}$. Moreover, the growing number of wind farms in coastal waters of medium depth $(<30 \mathrm{~m})$ has added to the soundscape at low frequencies and resulted in behavioral reactions of nearby marine mammals.

Climate change has also affected the ocean soundscape. The emission of carbon into the atmosphere through the effects of fossil-fuel combustion and industrial processes has increased atmospheric concentrations of carbon dioxide $\left(\mathrm{CO}_{2}\right)$. Ocean acidification, which occurs when $\mathrm{CO}_{2}$ in the atmosphere reacts with water to create carbonic acid
$\left(\mathrm{H}_{2} \mathrm{CO}_{3}\right)$, has increased. The attenuation of low-frequency sound in the sea is $\mathrm{pH}$ dependent; specifically, the higher the $\mathrm{pH}$, the greater the attenuation. Thus, as the ocean has become more acidic (lower $\mathrm{pH}$ ) due to increasing $\mathrm{CO}_{2}$ emissions, the attenuation has diminished and low-frequency sounds propagate farther, making the ocean noisier. Recent investigations have estimated that the noise at $3 \mathrm{kHz}$ would increase by $30 \%$ if the $\mathrm{pH}$ decreased from 8.0 to 7.4 .

Modeling tools traditionally used in underwater acoustics have undergone a necessary transformation; these tools include propagation, noise, reverberation, and sonar-performance models. Advanced modeling techniques now include forward and inverse applications, integratedmodeling approaches, nonintrusive measurements and novel processing methods. The flow of the sonar modeling processes was used to demonstrate advances in modeling technology relevant to assessments of the ocean soundscape. A 32-year baseline inventory of modeling techniques was updated with the latest developments, including basic mathematics and references to the key literature, to guide soundscape practitioners to the most efficient modeling techniques for any given application.

Advanced processing methods included integrated modeling approaches that combine marine-mammal movement simulators with underwater acoustic models to predict (and thus minimize and mitigate) the potential effect of sound on marine mammals. Advances have been achieved using energy-flux and waveguide-invariant techniques that can simplify interpretation of channel models. Nonintrusive measurement approaches included new acoustic transmission options to minimize marine-mammal impacts. Collision avoidance techniques have proved useful in areas of high cetacean and vessel density. Finally, adjoint modeling, stochastic resonance, optimization techniques, and chaos were shown to facilitate understanding of advance underwater acoustic modeling results.

\section{Abbreviations}

\begin{tabular}{|c|c|}
\hline 1D: & One-dimensional \\
\hline 2D: & Two-dimensional \\
\hline 3D: & Three Dimensional \\
\hline 3DWAPE: & 3D wide-angle parabolic equation \\
\hline 3MB: & $\begin{array}{l}\text { Marine mammal movement and } \\
\text { behavior }\end{array}$ \\
\hline ACM: & Association for computing machinery \\
\hline ACO: & Ant colony optimization \\
\hline AIM: & Acoustic integration model \\
\hline ARAMIS: & $\begin{array}{l}\text { Array response advanced modal } \\
\text { integrated simulator }\end{array}$ \\
\hline ARTEMIS: & $\begin{array}{l}\text { Adiabatic reverberation and target echo } \\
\text { mode incoherent sum }\end{array}$ \\
\hline ASA: & Acoustical Society of America \\
\hline ASPECT: & $\begin{array}{l}\text { Active system performance estimate } \\
\text { computer tool }\end{array}$ \\
\hline AUV: & Autonomous underwater vehicle \\
\hline BISTAR: & $\begin{array}{l}\text { Incoherent bistatic reverberation for } \\
\text { range-dependent environments }\end{array}$ \\
\hline
\end{tabular}




\begin{tabular}{|c|c|c|c|}
\hline BLM: & $\begin{array}{l}\text { Bureau of Land Management (now } \\
\text { BOEMRE) }\end{array}$ & IARIA: & $\begin{array}{l}\text { International Academy, Research, and } \\
\text { Industry Association }\end{array}$ \\
\hline BMT: & British Maritime Technology Ltd & ICC: & International Conference on \\
\hline \multirow[t]{3}{*}{ BOEMRE: } & Bureau of Ocean Energy Management, & & Communications \\
\hline & Regulation and Enforcement (formerly & IECM: & Integral equation coupled-mode \\
\hline & BLM) & IEEE: & Institute of Electrical and Electronics \\
\hline \multirow[t]{3}{*}{ BORIS-SSA: } & Bottom reverberation from & & Engineers \\
\hline & inhomogeneities and & IEER: & Improved extended echo ranging \\
\hline & surfaces-small-slope approximation & Integrated Mode: & Multipath expansion method extended \\
\hline CALYPSO: & Model operating system & & to range-dependent environments \\
\hline Cartesian 3DPE: & $\begin{array}{l}\text { 3DPE Employing Cartesian } \\
\text { Coordinates in the Numerical Scheme }\end{array}$ & IOMEDEX: & $\begin{array}{l}\text { Ionian Sea/Mediterranean Sea Exercise } \\
\text { (part of LRAPP) }\end{array}$ \\
\hline CEE: & Controlled exposure experiments & IRFC: & Industry Research Funders Coalition \\
\hline CiSE: & $\begin{array}{l}\text { Computational intelligence and } \\
\text { software engineering }\end{array}$ & ISAAC: & $\begin{array}{l}\text { Impact on Species from Anthropogenic } \\
\text { Acoustic Channels }\end{array}$ \\
\hline \multirow{3}{*}{$\begin{array}{l}\text { CMM: } \\
\text { CORDA: }\end{array}$} & Caractérisation du Milieu Marin & JASA: & Journal of the Acoustical Society of \\
\hline & Centre for Operational Research and & & America \\
\hline & Defence Analysis & LRAPP: & Long Range Acoustic Propagation \\
\hline \multirow{2}{*}{ COWRIE: } & Collaborative Offshore Wind Energy & & Project \\
\hline & Research Into the Environment & LSMS: & Life system modeling and simulation \\
\hline C-SNAP-REV: & $\begin{array}{l}\text { Reverberation using the C-SNAP } \\
\text { Normal-Mode Model }\end{array}$ & LYBIN: & $\begin{array}{l}\text { Range-dependent ray-theoretical } \\
\text { propagation model }\end{array}$ \\
\hline \multirow{7}{*}{$\begin{array}{l}\text { CW: } \\
\text { CZMA: } \\
\text { DANM: } \\
\text { dB: } \\
\text { DMOS: } \\
\text { DRDC: }\end{array}$} & Continuous wave & MATLAB: & Matrix Laboratory \\
\hline & Coastal zone Management Act & & (Mathworks, Inc.) \\
\hline & Dynamic ambient noise model & MCM: & Mine countermeasures \\
\hline & Decibel & METOC: & Meteorology and oceanography \\
\hline & DRDC Atlantic model operating system & MINEOS: & MSASM interactive execution and \\
\hline & Defence Research and Development & & optimization system \\
\hline & Canada & MMPA: & Marine Mammal Protection Act \\
\hline \multirow[t]{2}{*}{ DREA: } & Defence Research Establishment & MMS: & Minerals Management Service \\
\hline & Atlantic (Canada) & MOC3D: & 3D Version of MOCASSIN \\
\hline \multirow[t]{2}{*}{ DSTO: } & Defence Science and Technology & MOCASSIN: & Monte Carlo Schall-Strahlen \\
\hline & Organisation (Australia) & & Intensitäten (Monte Carlo Sound Ray \\
\hline EIA: & Environmental impact assessment & & Intensities) \\
\hline ESA: & Endangered Species Act & MOD: & Ministry of Defence \\
\hline ESME: & $\begin{array}{l}\text { Effects of sound on the marine } \\
\text { environment }\end{array}$ & MODRAY: & $\begin{array}{l}\text { Maritime Operations Division } \\
\text { Ray-tracer }\end{array}$ \\
\hline ESPRESSO: & $\begin{array}{l}\text { Extensible performance and evaluation } \\
\text { suite for sonar }\end{array}$ & $\begin{array}{l}\text { MONM: } \\
\text { MONM3D: }\end{array}$ & $\begin{array}{l}\text { Marine Operations Noise Model } \\
\text { 3D PE Model for MONM }\end{array}$ \\
\hline ETOP05: & Earth topography five-minute grid & MONOGO: & Reverberation Module in SWAMI \\
\hline \multirow[t]{2}{*}{ FeyRay: } & Broadband, range-dependent & M\&S: & Modeling and Simulation \\
\hline & Gaussian-beam propagation model & MTS: & Marine Technology Society \\
\hline \multirow[t]{3}{*}{ FFI: } & Forsvarets forskningsinstitutt & MURAL: & Multistatic reverberation algorithm \\
\hline & (Norwegian Defence Research & $\mathrm{N} \times 2 \mathrm{D}:$ & Quasi-3D modeling approach \\
\hline & Establishment) & NATO: & North Atlantic Treaty Organization \\
\hline FFP: & Fast field program & NEMO: & NUWC Exposure Model \\
\hline FM: & Frequency modulation & NEPA: & National Environmental Policy Act \\
\hline FORTRAN: & Formula translation & NGDC: & National Geophysical Data Center \\
\hline \multirow[t]{2}{*}{ GDEM: } & Generalized digital environmental & NMFS: & National Marine Fisheries Service \\
\hline & model & NOAA: & National Oceanic and Atmospheric \\
\hline GIS: & Geographic information system & & Administration \\
\hline GmbH: & Gesellschaft mit beschränkter Haftung & NOGRP: & Fast normal mode (monostatic) \\
\hline GOATS: & Generic Ocean Array Technology Sonar & & reverberation model \\
\hline GUI: & Graphical User Interface & NSPE: & Navy Standard Parabolic Equation \\
\hline HYREV: & $\begin{array}{l}\text { HanYang University Reverberation } \\
\text { Model }\end{array}$ & NTNU: & $\begin{array}{l}\text { Norwegian University of Science and } \\
\text { Technology }\end{array}$ \\
\hline IAGC: & $\begin{array}{l}\text { International Association of } \\
\text { Geophysical Contractors }\end{array}$ & NURC: & $\begin{array}{l}\text { NATO Undersea Research Centre } \\
\text { (formerly SACLANTCEN) }\end{array}$ \\
\hline
\end{tabular}




\begin{tabular}{|c|c|c|c|}
\hline \multirow[t]{2}{*}{ US } & \multirow{2}{*}{$\begin{array}{l}\text { Naval Underwater Systems Center (now } \\
\text { NUWC) }\end{array}$} & \multicolumn{2}{|c|}{ SUPREMO: Multistatic sonar model } \\
\hline & & SWAMI: & Shallow Water Active-Sonar Modelling \\
\hline NUWC: & Naval Undersea Warfare Center & & Initiative \\
\hline & (formerly NUSC) & SWAMP: & Shallow Water Acoustic Modal \\
\hline OASES: & Ocean acoustics and seismic & & Propagation \\
\hline & exploration synthesis & SWSS: & Sperm Whale Seismic Study \\
\hline OASES-3D: & Version of OASES incorporating 3D & TDA: & Tactical decision aid \\
\hline & scattering effects & TIAPS: & Towed integrated active-passive sonar \\
\hline OBIS: & Ocean biogeographic information & TRM: & Time-reversal mirror \\
\hline & system & TTS: & Temporary threshold shift \\
\hline OCS: & Outer continental shelf & UAIM: & Underwater acoustic imaging model \\
\hline ONR: & Office of Naval Research & UDT: & Undersea defence technology \\
\hline OWWE: & One-way wave equation & USWTR: & Undersea warfare training range \\
\hline PAREQ: & Parabolic equation model & UUV: & Unmanned undersea vehicle \\
\hline PAREQ-REV: & $\begin{array}{l}\text { Reverberation using the PAREQ } \\
\text { parabolic equation model }\end{array}$ & $\begin{array}{l}\text { WHOI: } \\
\text { WKB: }\end{array}$ & $\begin{array}{l}\text { Woods Hole Oceanographic Institution } \\
\text { Wentzel, Kramers, and Brillouin }\end{array}$ \\
\hline PDF: & Probability density (or distribution) & WUWNet: & Workshop on Underwater Networks \\
\hline $\begin{array}{l}\text { PDPE: } \\
\text { PE: }\end{array}$ & $\begin{array}{l}\text { Pseudo-differential PE } \\
\text { Parabolic equation }\end{array}$ & & $\begin{array}{l}\text { combined with full-field modeling of } \\
\text { seabed interactions. }\end{array}$ \\
\hline
\end{tabular}

\section{References}

[1] K. D. LePage, P. Neumann, and C. W. Holland, "Broad-band time domain modeling of sonar clutter in range dependent waveguides," in in Proceedings of the MTS/IEEE Oceans 2006 Conference (OCEANS'06), Boston, Mass, USA, September 2006.

[2] I. F. Akyildiz, D. Pompili, and T. Melodia, "Challenges for efficient communication in underwater acoustic sensor networks," ACM SIGBED Review, vol. 1, no. 2, pp. 3-8, 2004.

[3] I. F. Akyildiz, D. Pompili, and T. Melodia, "Underwater acoustic sensor networks: research challenges," Ad Hoc Networks, vol. 3, no. 3, pp. 257-279, 2005.

[4] D. Frye, L. Freitag, R. Detrick et al., "An acoustically linked moored-buoy ocean observatory," EOS, Transactions, American Geophysical Union, vol. 87, no. 22, pp. 213-218, 2006.

[5] Z. Han, Y. L. Sun, and H. Shi, "Cooperative transmission for underwater acoustic communications," in Proceedings of the IEEE International Conference on Communications, (ICC'08), pp. 2028-2032, Beijing, China, 2008.

[6] V. Chandrasekhar, W. K. G. Seah, Y. S. Choo, and H. V. Ee, "Localization in underwater sensor networks-survey and challenges," in Proceedings of the 1st ACM International Workshop on Underwater Networks (WUWNet'06), pp. 3340, Los Angeles, Calif, USA, September 2006.

[7] J. Wang, P. Cai, and D. Yuan, "An underwater acoustic channel simulator for UUV communication performance testing," in Proceedings of the IEEE International Conference on Information and Automation, pp. 2286-2290, Harbin, China, 2010.

[8] J. G. Graver, Underwater gliders: dynamics, control and design, $\mathrm{PhD}$ dissertation, Department of Mechanical and Aerospace Engineering, Princeton University, Princeton, NJ, USA, 2005.

[9] A. Jochens, D. Biggs, D. Engelhaupt et al., "Sperm whale seismic study in the Gulf of Mexico," Summary Report, 20022004 OCS Study MMS 2006-034, US Department of the Interior, Minerals Management Service, Gulf of Mexico OCS Region, New Orleans, La, USA, 2006. 
[10] A. Thode, D. K. Mellinger, S. Stienessen, A. Martinez, and K. Mullin, "Depth-dependent acoustic features of diving sperm whales (Physeter macrocephalus) in the Gulf of Mexico," Journal of the Acoustical Society of America, vol. 112, no. 1, pp. 308-321, 2002.

[11] W. M. Carey and R. B. Evans, Ocean Ambient Noise: Measurement and Theory, Springer, New York, NY, USA, 2011.

[12] R. K. Andrew, B. M. Howe, J. A. Mercer, and M. A. Dzieciuch, "Ocean ambient sound: comparing the 1960s with the 1990s for a receiver off the California coast," Acoustic Research Letters Online, vol. 3, pp. 65-70, 2002.

[13] M. A. McDonald, J. A. Hildebrand, and S. M. Wiggins, "Increases in deep ocean ambient noise in the Northeast Pacific west of San Nicolas Island, California," Journal of the Acoustical Society of America, vol. 120, no. 2, pp. 711-718, 2006.

[14] M. A. McDonald, J. A. Hildebrand, S. M. Wiggins, and D. Ross, "A 50 year comparison of ambient ocean noise near San Clemente Island: a bathymetrically complex coastal region off Southern California," Journal of the Acoustical Society of America, vol. 124, no. 4, pp. 1985-1992, 2008.

[15] J. Nedwell and D. Howell, "A review of offshore windfarm related underwater noise sources," Report 544R0308, Subacoustech Ltd, commissioned by COWRIE (Collaborative Offshore Wind Research Into the Environment), Hampshire, UK, 2004.

[16] D. Rouseff and D. Tang, "Internal waves as a proposed mechanism for increasing ambient noise in an increasingly acidic ocean," Journal of the Acoustical Society of America, vol. 127, no. 6, pp. EL235-EL239, 2010.

[17] E. McCarthy, International Regulation of Underwater Sound: Establishing Rules and Standards to Address Ocean Noise Pollution, Kluwer Academic Publishers, Dordrecht, The Netherlands, 2004.

[18] National Research Council, Ocean Noise and Marine Mammals, The National Academies Press, Washington, DC, USA, 2003.

[19] National Research Council, Marine Mammal Populations and Ocean Noise: Determining When Noise Causes Biologically Significant Effects, The National Academies Press, Washington, DC, USA, 2005.

[20] J. F. Grassle, "The ocean biogeographic information system (OBIS): an on-line, worldwide atlas for accessing, modeling and mapping marine biological data in a multidimensional geographic context," Oceanography, vol. 13, no. 3, pp. 5-7, 2000.

[21] S. Finette, "Embedding uncertainty into ocean acoustic propagation models," Journal of the Acoustical Society of America, vol. 117, no. 3 I, pp. 997-1000, 2005.

[22] J. W. Lawson, "The use of sound propagation models to determine safe distances from a seismic sound energy source," Research Document 2009/060, Department of Fisheries and Oceans, Canadian Science Advisory Secretariat, 2009.

[23] P. C. Etter, Underwater Acoustic Modeling and Simulation, Spon Press, London, UK, 3rd edition, 2003.

[24] R.J. Howard, T. Foreman, and D. Clark, "Architectural and design considerations in propagation model selection and design, simulation interoperability standards organization," in Proceedings of the Simulation Interoperability Workshop, no. 00S-SIW-054, 2000.

[25] F. C. Newman, A. C. Biondo, M. D. Mandelberg, C. C. Matthews, and J. R. Rottier, "Enhancing realism in computer simulations: environmental effects," Johns Hopkins APL Technical Digest, vol. 23, no. 4, pp. 443-453, 2002.

[26] J. Collins, T. Foreman, and D. Speicher, "A new design for a sonar environmental effects server," in Proceedings of the Simulation Interoperability Workshop, no. 02F-SIW-114, Simulation Interoperability Standards Organization, 2002.

[27] T. Foreman and D. Speicher, "Expanded sonar environmental acoustic effects server capabilities for fleet battle experiments," in Proceedings of the Simulation Interoperability Workshop, no. 03F-SIW-062, Simulation Interoperability Standards Organization, 2003.

[28] J. B. Collins and C. G. Scannell, "Natural environment data services in distributed modeling and simulation," in NetCentric Approaches to Intelligence and National Security, R. Ladner and F. E. Petry, Eds., pp. 149-174, Springer, New York, NY, USA, 2005.

[29] J. M. Hovem, "PlaneRay: an acoustic underwater propagation model based on ray tracing and plane-wave reflection coefficients," FFI-rapport 2008/00610, Forsvarets forskningsinstitutt/Norwegian Defence Research Establishment (FFI), 2008.

[30] J. M. Hovem, S. Yan, X. Bao, and H. Dong, "Modeling underwater communication links," in Proceedings of the 2 nd International Conference on Sensor Technologies and Applications (SENSORCOMM '08), pp. 679-686, IEEE Computer Society, 2008.

[31] J. M. Hovem and H. Dong, "PlaneRay: an underwater acoustic propagation model using ray tracing and plane wave reflection coefficients," Journal of the Acoustical Society of America, vol. 120, p. 3221, 2006.

[32] J. M. Hovem and D. P. Knobles, "A range-dependent propagation model based on a combination of ray theory and plane-wave reflection coefficients," Journal of the Acoustical Society of America, vol. 112, p. 2393, 2002.

[33] J. M. Hovem and D. P. Knobles, "A range dependent propagation model based on a combination of ray theory and plane wave reflection coefficients," in Proceedings of the 10th International Congress on Sound and Vibration, pp. 25932600, Stockholm, Sweden, July 2003.

[34] S. A. Stotts, D. P. Knobles, R. A. Koch, D. E. Grant, K. C. Focke, and A. J. Cook, "Geoacoustic inversion in rangedependent ocean environments using a plane wave reflection coefficient approach," Journal of the Acoustical Society of America, vol. 115, no. 3, pp. 1078-1102, 2004.

[35] U. Kristiansen, "Sound propagation in regions of variable oceanography - a summary of student work at NTNU," FFIrapport 2010/00812, Norwegian Defence Research Establishment, 2010.

[36] H.S. Olsen, "Lydutbredelse i havområder med avstandsavhengig oseanografi," Norges teknisk-naturvitenskapelige universitet, Institutt for elektronikk og telekommunikasjon, Trondheim, Norway, 2008.

[37] T. S. Semantic, "RAYSON: underwater acoustic rays software," Product description literature, Semantic TS , Sanary, France, 2002.

[38] C. Viala, C. Noël, and G. Lapierre, "RAYSON: a real time underwater communication simulator and performance estimator," in Proceedings of the 7th French Workshop on Underwater Acoustics, Brest, France, 2004.

[39] C. Viala, C. Noël, Y. Stéphan, and M. Asch, "Real-time geoacoustic inversion of large band signals," in Proceedings of the IEEE Oceans 2005 Europe Conference, pp. 1392-1395, Brest, France, 2005.

[40] C. Viala, C. Noël, Y. Stéphan, and M. Asch, "Real-time geoacoustic inversion of broad band signals in deep water," 
in Proceedings of the Caractérisation du Milieu Marin (CMM'06), Brest, France, 2006.

[41] E. Svensson, I. Karasalo, and J.-P. Hermand, "Hybrid raytrace modelling of an underwater acoustics communication channel," in Proceedings of the 7th European Conference on Underwater Acoustics, pp. 1211-1216, Delft, The Netherlands, 2004.

[42] D. D. Ellis, "A two-ended shooting technique for calculating normal modes in underwater acoustic propagation," DREA Report 85/105, Defence Research Establishment Atlantic, Nova Scotia, Canada, 1985.

[43] S. A. Stotts, D. P. Knobles, and R.A. Koch, "Scattering in a Pekeris waveguide from a rough bottom using a two-way coupled mode approach," Journal of the Acoustical Society of America, vol. 129, no. 5, pp. EL172-EL178, 2011.

[44] N. A. Sidorovskaia, "A new normal mode program SWAMP as a tool for modeling scattering effects in oceanic waveguides," in Modelling and Experimental Measurements in Acoustics III, D. Almorza, C. A. Brebbia, and R. Hernandez, Eds., pp. 267-275, WIT Press, Southampton, UK, 2003.

[45] N. A. Sidorovskaia, "Systematic studies of pulse propagation in ducted oceanic waveguides in normal mode representation," The European Physical Journal, Applied Physics, vol. 25, no. 2, pp. 113-131, 2004.

[46] I. M. Tamendarov and N. A. Sidorovskaia, "Unified acoustic model for simulating propagation and scattering effects in oceanic waveguides," Journal of the Acoustical Society of America, vol. 116, p. 2527, 2004.

[47] C. A. Clark, "Acoustic wave propagation in horizontally variable media," IEEE Journal of Oceanic Engineering, vol. 30, no. 1, pp. 188-197, 2005.

[48] H. Schmidt, A. Maguer, E. Bovio et al., "Generic oceanographic array technologies (GOATS) '98 - Bistatic seabed scattering measurements using autonomous underwater vehicles," Report SR-302, SACLANT Undersea Research Centre, La Spezia, Italy, 1998.

[49] H. Schmidt, I. Veljkovic, and M. Zampolli, "Bistatic scattering from buried targets in shallow water-experiment and modelling," in Proceedings of the 7th European Conference on Underwater Acoustics, Delft, The Netherlands, 2004.

[50] H. Schmidt, "Bistatic scattering from buried targets in shallow water," in Proceedings of the Autonomous Underwater Vehicle and Ocean Modelling Networks (GOATS'00), E. Bovio, R. Tyce, and H. Schmidt, Eds., no. CP-46, SACLANT Undersea Research Centre, 2001.

[51] H. Schmidt, "OASES Version 3.1 user guide and reference manual," Department of Ocean Engineering, Massachusetts Institute of Technology, Cambridge, Mass, USA, 2004.

[52] D. J. Thomson and N. R. Chapman, "WIDE-angle splitstep algorithm for the parabolic equation," Journal of the Acoustical Society of America, vol. 74, no. 6, pp. 1848-1854, 1983.

[53] T. F. Duda, "Initial results from a Cartesian threedimensional parabolic equation acoustical propagation code," Tech. Rep. WHOI-2006-14, Woods Hole Oceanographic Institution, Woods Hole, Mass, USA, 2006.

[54] L. Y. S. Chiu, Y.-T. Lin, C.-F. Chen, T. F. Duda, and B. Calder, "Focused sound from three-dimensional sound propagation effects over a submarine canyon," Journal of the Acoustical Society of America, vol. 129, no. 6, pp. EL260-EL266, 2011.

[55] M. E. Austin and N. R. Chapman, "The use of tessellation in three-dimensional parabolic equation modeling," Journal of Computational Acoustics, vol. 19, pp. 221-239, 2011.

[56] D. Mikhin, "Exact discrete nonlocal boundary conditions for high-order Padé parabolic equations," Journal of the Acoustical Society of America, vol. 116, no. 5, pp. 2864-2875, 2004.
[57] O. A. Godin, "Reciprocity and energy conservation within the parabolic approximation," Wave Motion, vol. 29, no. 2, pp. 175-194, 1999.

[58] L. T. Fialkowski, J. F. Lingevitch, J. S. Perkins, D. K. Dacol, and M. D. Collins, "Geoacoustic inversion using a rotated coordinate system and simulated annealing," IEEE Journal of Oceanic Engineering, vol. 28, no. 3, pp. 370-379, 2003.

[59] L. Zhang, L. Da, and Y. Zhou, "A new ocean acoustic model in computational oceanographic physics," in in Proceedings of the International Conference on Computational Intelligence and Software Engineering, CiSE'09, Wuhan, China, December 2009.

[60] F. Sturm and J. A. Fawcett, "On the use of higher-order azimuthal schemes in 3-D PE modeling," Journal of the Acoustical Society of America, vol. 113, no. 6, pp. 3134-3145, 2003.

[61] F. Sturm, "Examination of signal dispersion in a 3-D wedgeshaped waveguide using 3DWAPE," Acta Acustica United with Acustica, vol. 88, no. 5, pp. 714-717, 2002.

[62] F. Sturm, "Numerical study of broadband sound pulse propagation in three-dimensional oceanic waveguides," Journal of the Acoustical Society of America, vol. 117, no. 3 I, pp. 10581079, 2005.

[63] W. Renner, "User's guide for the ANDES model," Tech. Rep. version 4.2, Science Applications International Corp., 1995.

[64] M. Moll, R. M. Zeskind, and W. L. Scott, "An algorithm for beam noise prediction," Report 3653, Bolt, Beranek and Newman, 1979.

[65] J. Arvelo, "Array response advanced modal integrated simulator (ARAMIS) user's guide, STX-98-010,” Johns Hopkins Applied Physics Laboratory, Laurel, Md, USA, 1998.

[66] J. R. Nedwell, J. Lovell, and A. W. H. Turnpenny, "Experimental validation of a species-specific behavioral impact metric for underwater noise," Journal of the Acoustical Society of America, vol. 118, p. 2019, 2005.

[67] BMT Cordah EIA and Environmental Services, Offshore Renewables. Noise Assessment and Modelling, Product Description Literature, Aberdeen, UK, 2010.

[68] M. H. Laurinolli, C. D. S. Tollefsen, S. A. Carr, and S. P. Turner, "Assessment of the effects of underwater noise from the proposed Neptune LNG project. Part (3): noise sources of the Neptune project and propagation modeling of underwater noise," LGL Report TA4200-3, JASCO Research Ltd for LGL Ltd, Ontario, Canada, 2005.

[69] S. W. Marshall and J. J. Cornyn, "Ambient-noise prediction. Vol. 1-Model of low-frequency ambient sea noise," Report 7755, Naval Research Laboratory, Washington, DC, USA, 1974.

[70] S. W. Marshall and J. J. Cornyn, "Ambient-noise prediction. Vol. 2-Model evaluation with IOMEDEX data," Report 7756, Naval Research Laboratory, Washington, DC, USA, 1974.

[71] Science Applications Inc., "Review of models of beam-noise statistics," SAI-78-696-WA, McLean, Va, USA, 1977.

[72] D. Long, "FANM/SIAM noise plot program," Ocean Data Systems Inc., Rockville, Md, USA, 1974.

[73] R. J. Urick, Principles of Underwater Sound, McGraw-Hill, New York, NY, USA, 3rd edition, 1983.

[74] J. W. Choi, K.-S. Yoon, J. Na, J.-S. Park, and Y.N. Na, "Shallow water high-frequency reverberation model," Journal of the Acoustical Society of Korea, vol. 21, pp. 671-678, 2002 (Korean).

[75] D.D. Ellis, Measurements and Analysis of Reverberation and Clutter Data, DRDC Atlantic ECR 2007-065, Defence Research and Development Canada, Atlantic, 2007.

[76] D. D. Ellis, "Normal-mode models OGOPOGO and NOGRP applied to the 2006 ONR reverberation modeling workshop 
problems," DRDC Atlantic TM 2006-289, Defence Research and Development Canada, Atlantic, 2008.

[77] J. F. Lingevitch, "A parabolic equation method for modeling rough interface reverberation," in Proceedings of the International Symposium on Underwater Reverberation and Clutter, P. L. Nielsen, C. H. Harrison, and J.-C. LeGac, Eds., Lerici, Italy, 2008.

[78] M. D. Collins and R. B. Evans, "A two-way parabolic equation for acoustic backscattering in the ocean," Journal of the Acoustical Society of America, vol. 91, no. 3, pp. 1357-1368, 1992.

[79] F. A. Milinazzo, C. A. Zala, and G. H. Brooke, "Rational square-root approximations for parabolic equation algorithms," Journal of the Acoustical Society of America, vol. 101, no. 2, pp. 760-766, 1997.

[80] G. Bouchage and K. D. LePage, "A shallow-water reverberation PE model," Acta Acustica United with Acustica, vol. 88, no. 5, pp. 638-641, 2002.

[81] K. LePage, "Monostatic reverberation in range dependent waveguides: the R-SNAP model," Report SR-363, SACLANT Undersea Research Centre, La Spezia, Italy, 2003.

[82] M. K. Prior, C. H. Harrison, and K. D. LePage, "Reverberation comparisons between RSNAP, SUPREMO and analytical solutions," Report SR-361, SACLANT Undersea Research Centre, La Spezia, Italy, 2002.

[83] C. Harrison, "ARTEMIS: a fast general environment reverberation model," in Proceedings of the International Symposium on Underwater Reverberation and Clutter, P. L. Nielsen and C. H. Harrison and J.-C. LeGac, Eds., p. 2008, Lerici, Italy, 2008.

[84] K. LePage, "Bottom reverberation in shallow water: coherent properties as a function of bandwidth, waveguide characteristics, and scatterer distributions," Journal of the Acoustical Society of America, vol. 106, no. 6, pp. 3240-3254, 1999.

[85] K. D. LePage, "Bistatic reverberation modeling for rangedependent waveguides," Journal of the Acoustical Society of America, vol. 112, pp. 2253-2254, 2002.

[86] K. D. LePage and C. H. Harrison, "Bistatic reverberation benchmarking exercise: BiStaR versus analytic formulas," Journal of the Acoustical Society of America, vol. 113, pp. 2333-2334, 2003.

[87] K. D. LePage and C. Harrison, "Effects of refraction on the prediction of bistatic reverberation in range dependent shallow water waveguides," Journal of the Acoustical Society of America, vol. 114, p. 2302, 2003.

[88] D. M. Fromm, "A computationally efficient multistatic reverberation algorithm," Journal of the Acoustical Society of America, vol. 129, p. 2631, 2011.

[89] V. Marconi, P. L. Nielsen, and C. Holland, "S-SCARAB: SACLANTCEN-Scattering reverberation and backscatter user guide and reference manual, NURC/SM-418," NATO Undersea Research Centre, La Spezia, Italy, 2004.

[90] F.-P. A. Lam, N. J. Konijnendijk, J. Groen, and D. G. Simons, "Non-Rayleigh wideband sonar reverberation modeling including hybrid multi-paths," in Proceedings of the The Oceans'06 MTS/IEEE-Boston Conference, Boston, Mass, USA, 2006.

[91] D. A. Abraham and A. P. Lyons, "Simulation of nonRayleigh reverberation and clutter," IEEE Journal of Oceanic Engineering, vol. 29, no. 2, pp. 362-374, 2004.

[92] E. Pouliquen, A. P. Lyons, and N. G. Pace, "The HelmholtzKirchhoff approach to modeling penetration of acoustic waves into rough seabeds," Journal of the Acoustical Society of America, vol. 104, p. 1762, 1998.
[93] G. Canepa and C. Berron, "Characterization of seafloor geoacoustic properties from multibeam data," in Proceedings of the MTS/IEEE Oceans Conference, Boston, Mass, USA, 2006.

[94] R. J. Soukup, G. Canepa, H. J. Simpson, J. E. Summers, and R. F. Gragg, "Small-slope simulation of acoustic backscatter from a physical model of an elastic ocean bottom," Journal of the Acoustical Society of America, vol. 122, no. 5, pp. 25512559, 2007.

[95] P. Staelens, Defining and modeling the limits of high-resolution underwater acoustic imaging, Doctoral dissertation, Universiteit Gent, Belgium, 2009.

[96] P. Blondel and N. G. Pace, "Bistatic sonars: sea trials, laboratory experiments and future surveys," Archives of Acoustics, vol. 34, no. 1, pp. 95-109, 2009.

[97] G. L. Davies, "Project 03F-1: phase I completion report," Memo SM-399, SACLANT Undersea Research Centre, La Spezia, Italy, 2002.

[98] M. Meyer and G. L. Davies, "A beam-based high-frequency reverberation model," Report SR-365, SACLANT Undersea Research Centre, La Spezia, Italy, 2002.

[99] G. L. Davies and E. P. Signell, "Espresso-scientific user guide," Report NURC-SP-2006-003, NATO Undersea Research Centre, La Spezia, Italy, 2006.

[100] G. L. Davies and E. P. Signell, "Espresso(m)—user guide," Report NURC-SP-2006-002, NATO Undersea Research Centre, La Spezia, Italy, 2006.

[101] S. Mjølsnes, LYBIN SGP-180(C)—Model Description, The Royal Norwegian Navy Materiel Command, Bergen, Norway, 2000.

[102] K.T. Hjelmervik and G.H. Sandsmark, "In ocean evaluation of low frequency active sonar systems," in Proceedings of the Acoustics '08 Conference, pp. 2839-2843, Paris, France, 2008.

[103] E. Dombestein, A. Gjersøe, and M. Bosseng, "LybinCom 6.0-description of the binary interface," FFI-rapport 2009/02267, Forsvarets forskningsinstitutt/Norwegian Defence Research Establishment, 2010.

[104] C. M. Ferla, C. Isoppo, G. Martinelli, and F. B. Jensen, "Performance assessment of the LYBIN-2.0 propagationloss model," Memo SM-384, SACLANT Undersea Research Centre, La Spezia, Italy, 2001.

[105] S. M. Ivansson, "Stochastic ray-trace computations of transmission loss and reverberation in 3-D range-dependent environments," in Proceedings of the 8th European Conference on Underwater Acoustics, pp. 131-136, Carvoeiro, Portugal, 2006.

[106] H. G. Schneider, "MOCASSIN: sound propagation and sonar range prediction model for shallow water environments. User's guide," Tech. Rep. 1990-9, Forschungsanstalt der Bundeswehr für Wasserschall- und Geophysik, Kiel, Germany, 1990.

[107] F. Sturm, S. Ivansson, Y.-M. Jiang, and N. R. Chapman, "Numerical investigation of out-of-plane sound propagation in a shallow water experiment," Journal of the Acoustical Society of America, vol. 124, no. 6, pp. EL341-EL346, 2008.

[108] K. Frith, "MODRAY underwater sound simulator user manual, Version 5.0," Australia Department of Defence, Defence Science and Technology Organisation, Maritime Operations Division, Aeronautical and Maritime Research Laboratory, Edinburgh, South Australia, 2003.

[109] Ebor Computing, "MODRAY, product description literature," Mile End, South Australia, 2005.

[110] R. Alksne, "Rapidly deployable systems (RDS) underwater acoustic telemetry trials report," Tech. Rep. DSTO-TN0259, Australia Department of Defence, Defence Science and 
Technology Organisation, Maritime Operations Division, Aeronautical and Maritime Research Laboratory, Victoria, Australia, 2000.

[111] D. McCammon, "Active sonar modelling with emphasis on sonar stimulators," Report CR 2004-130 Defence Research and Development Canada-Atlantic, 2004.

[112] A. Baldacci and C. H. Harrison, "SUPREMO prototype version 01 user's guide, M-141," SACLANT Undersea Research Centre, La Spezia, Italy, 2002.

[113] C. H. Harrison, "Scattering strength uncertainty," Journal of the Acoustical Society of America, vol. 112, p. 2253, 2002.

[114] C. H. Harrison, "SUPREMO: a multistatic sonar performance model, Memo SM-396," SACLANT Undersea Research Centre, La Spezia, Italy, 2002.

[115] C. H. Harrison, "Closed-form expressions for ocean reverberation and signal excess with mode stripping and Lambert's law," Journal of the Acoustical Society of America, vol. 114, no. 5, pp. 2744-2756, 2003.

[116] M. K. Prior and A. Baldacci, "Comparison between predictions made by the SUPREMO sonar performance model and measured data," Report SR-429, SACLANT Undersea Research Centre, La Spezia, Italy, 2005.

[117] M. K. Prior, "SUPREMO v.2.0 user guide," Report NURCFR-2007-009, NATO Undersea Research Centre, La Spezia, Italy, 2007.

[118] M. K. Prior, “SUPREMO v.2.0 program description,” Report NURC-FR-2007-011, NATO Undersea Research Centre, La Spezia, Italy, 2007.

[119] J. A. Theriault and D. D. Ellis, "Shallow-water lowfrequency active sonar modelling issues," in Proceedings of the MTS/IEEE Oceans '97 Conference, p. 678, 672, Halifax, Canada, 1997.

[120] J. A. Theriault, S. Pecknold, N. Collison, and C. Calnan, "Modelling multibeam reverberation with an $\mathrm{N} \times 2 \mathrm{D}$ model," in Proceedings of the 8th European Conference on Underwater Acoustics, Carvoeiro, Portugal, 2006.

[121] C. Calnan, "DMOS-Bellhop Extension," Tech. Rep. CR 2006-005, DRDC Atlantic, Defence Research and Development Canada-Atlantic, 2006.

[122] M. D. Wagstaff, R. W. Meredith, and H. A. Terrill-Stolper, "Multi-beam high frequency imaging in a range-dependent environment," in Proceedings of the MTS/IEEE Oceans '97 Conference, pp. 927-931, Halifax, Canada, 1997.

[123] M. A. Kalogerakis, E. K. Skarsoulis, J. S. Papadakis et al., "An integrated computer system for underwater acoustic detection analysis," in Proceedings of the Undersea Defence Technology Conference, (UDT'04), Nice, France, 2004.

[124] H. J. Shyu and R. Hillson, "A software workbench for estimating the effects of cumulative sound exposure in marine mammals," IEEE Journal of Oceanic Engineering, vol. 31, no. 1, pp. 8-21, 2006.

[125] M. Siderius and M. B. Porter, "Modeling techniques for marine-mammal risk assessment," IEEE Journal of Oceanic Engineering, vol. 31, no. 1, pp. 49-60, 2006.

[126] "Applied Radar \& Sonar Technologies GmbH, Sonar performance prediction system (SPPS)," product description literature, Bremerhaven, Germany, 2002.

[127] Applied Hydro-Acoustics Research Inc., "ASPECT user's guide," Version 2.0.1 Build 664, Centreville, VA, USA, 2001.

[128] A. S. Frankel, W. T. Ellison, and J. Buchanan, "Application of the Acoustic Integration Model (AIM) to predict and minimize environmental impacts," in in Proceedings of the MTS/IEEE Oceans '02 Conference, pp. 1438-1443, Biloxi, Miss, USA, October 2002.
[129] D. S. Houser, "A method for modeling marine mammal movement and behavior for environmental impact assessment," IEEE Journal of Oceanic Engineering, vol. 31, no. 1, pp. 76-81, 2006.

[130] G. Haralabus and A. Baldacci, "Impact of seafloor and water column parameter variations on signal-to-background ratio estimates-a sensitivity analysis based on sonar performance modeling," in Proceedings of the 8th European Conference on Underwater Acoustics, 2006, Carvoeiro, Portugal.

[131] P. D. Ward, P. Varley, and T. Clarke, "Detecting marine mammals using active sonar-a theoretical consideration," in Proceedings of the Institute of Acoustics, vol. 26, part 6, no. Symposium on Bio-Sonar Systems and Bioacoustics, 2004.

[132] D. E. Weston, "Acoustic flux formulas for range-dependent ocean ducts," Journal of the Acoustical Society of America, vol. 68, no. 1, pp. 269-281, 1980.

[133] X. Lurton, An Introduction to Underwater Acoustics: Principles and Applications, Springer, New York, NY, USA, 2002.

[134] C. W. Holland, "Propagation in a waveguide with rangedependent seabed properties," Journal of the Acoustical Society of America, vol. 128, no. 5, pp. 2596-2609, 2010.

[135] M. G. Brown, F. J. Beron-Vera, I. Rypina, and I. A. Udovydchenkov, "Rays, modes, wavefield structure, and wavefield stability," Journal of the Acoustical Society of America, vol. 117, no. 3, pp. 1607-1610, 2005.

[136] K. L. Cockrell and H. Schmidt, "A relationship between the waveguide invariant and wavenumber integration," Journal of the Acoustical Society of America, vol. 128, no. 1, pp. EL63EL68, 2010.

[137] R. McHugh, D. McLaren, M. Wilson, and R. Dunbar, "The underwater environment-a fluctuating acoustic medium rich in marine life. Implications for active military sonar," Acta Acustica United with Acustica, vol. 91, no. 1, pp. 51-60, 2005.

[138] G. B. Deane and M. D. Stokes, "Model calculations of the underwater noise of breaking waves and comparison with experiment," Journal of the Acoustical Society of America, vol. 127, no. 6, pp. 3394-3410, 2010.

[139] W. E. Brown and M. L. Barlett, "Midfrequency 'throughthe-sensor' scattering measurements: a new approach," IEEE Journal of Oceanic Engineering, vol. 30, no. 4, pp. 733-747, 2005.

[140] E. Delory, M. André, J. L. Navarro Mesa, and M. Van Der Schaar, "On the possibility of detecting surfacing sperm whales at risk of collision using others' foraging clicks," Journal of the Marine Biological Association of the United Kingdom, vol. 87, no. 1, pp. 47-58, 2007.

[141] J.-P. Hermand, M. Meyer, M. Asch, and M. Berrada, "Adjoint-based acoustic inversion for the physical characterization of a shallow water environment," Journal of the Acoustical Society of America, vol. 119, no. 6, pp. 3860-3871, 2006.

[142] M. Meyer and J.-P. Hermand, "Backpropagation techniques in ocean acoustic inversion: time reversal, retrogation and adjoint modeling - a review," in Acoustic Sensing Techniques for the Shallow Water Environment: Inversion methods and experiments, A. Caiti, N. R. Chapman, J.-P. Hermand, and S.M. Jesus, Eds., pp. 29-46, Springer, New York, NY, USA, 2006.

[143] P. Hursky, M. B. Porter, B. D. Cornuelle, W. S. Hodgkiss, and W. A. Kuperman, "Adjoint modeling for acoustic inversion," Journal of the Acoustical Society of America, vol. 115, no. 2, pp. 607-619, 2004. 
[144] L. Gammaitoni, P. Hänggi, P. Jung, and F. Marchesoni, "Stochastic resonance," Reviews of Modern Physics, vol. 70, no. 1, pp. 223-287, 1998.

[145] H. Zhang, B. Xu, Z.-P. Jiang, and X. Wu, “Target detection in shallow-water reverberation based on parameter-induced stochastic resonance," Journal of Physics A, vol. 41, no. 10, Article ID 105003, 2008.

[146] B. Xu, L. Zeng, and J. Li, "Application of stochastic resonance in target detection in shallow-water reverberation," Journal of Sound and Vibration, vol. 303, no. 1-2, pp. 255-263, 2007.

[147] A. V. van Leijen, The sound of sediments: acoustic sensing in uncertain environments, $\mathrm{PhD}$ dissertation, Universiteit van Amsterdam, The Netherlands, 2010.

[148] B. B. Thompson, R. J. Marks, M. A. El-Sharkawi, W. J. Fox, and R. T. Miyamoto, "Inversion of neural network underwater acoustic model for estimation of bottom parameters using modified particle swarm optimizers," in in Proceedings of the IEEE International Joint Conference on Neural Networks, pp. 1301-1306, Portland, Ore, USA, July 2003.

[149] Z.-H. Michalopoulou and U. Ghosh-Dastidar, "Tabu for matched-field source localization and geoacoustic inversion," Journal of the Acoustical Society of America, vol. 115, no. 1, pp. 135-145, 2004.

[150] F. Glover and M. Laguna, Tabu Search, Kluwer Academic Publishers, Dordrecht, The Netherlands, 1997.

[151] A. L. Virovlyansky, "Signal travel times along chaotic rays in long-range sound propagation in the ocean," Acoustical Physics, vol. 51, no. 3, pp. 271-281, 2005.

[152] D. V. Makarov, M. Y. Uleysky, and S. V. Prants, "Ray chaos and ray clustering in an ocean waveguide," Chaos, vol. 14, no. 1, pp. 79-95, 2004.

[153] D. Makarov, S. Prants, A. Virovlyansky, and G. Zaslavsky, Ray and Wave Chaos in Ocean Acoustics: Chaos in Waveguides, World Scientific Publishing, Singapore, 2010. 

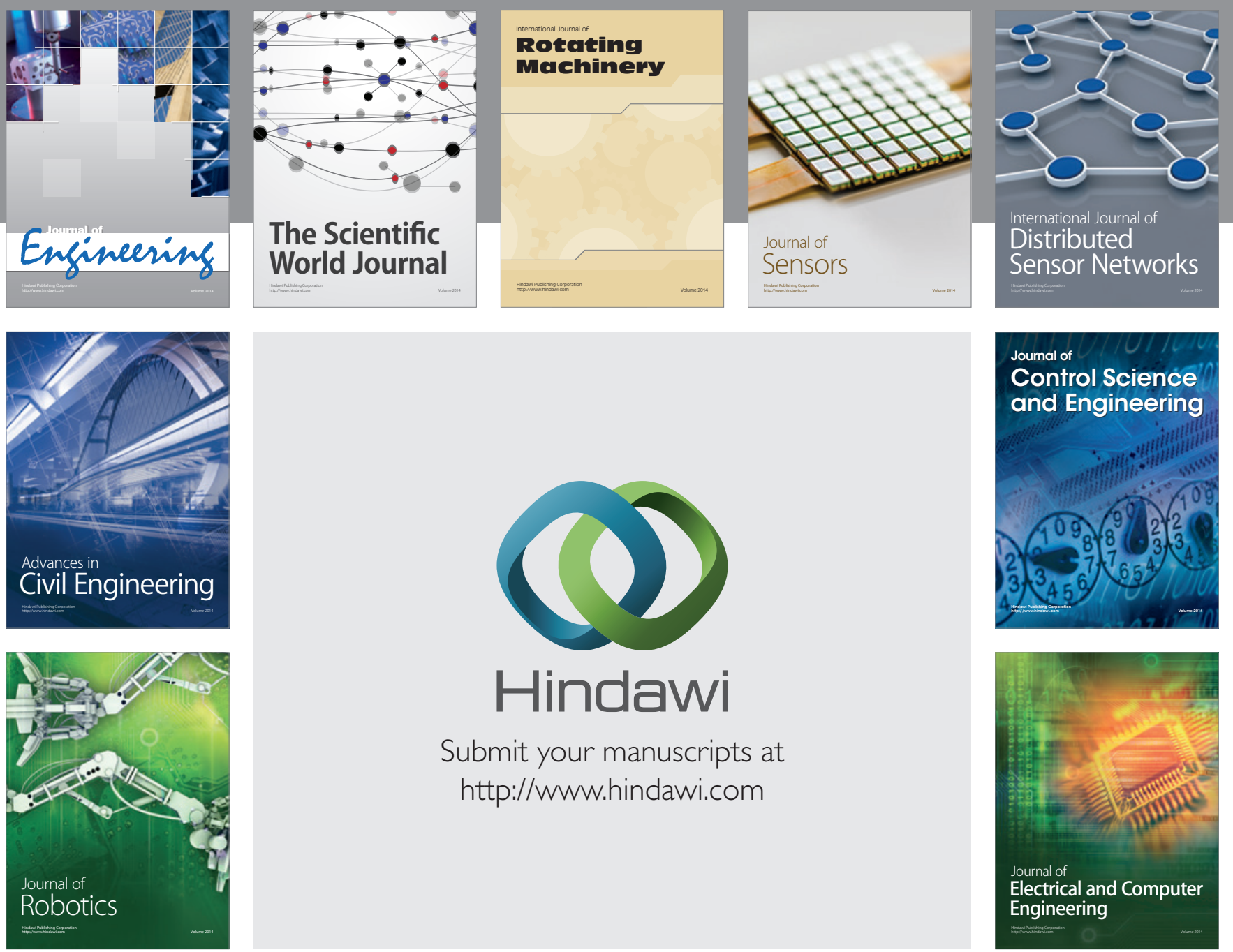

Submit your manuscripts at

http://www.hindawi.com
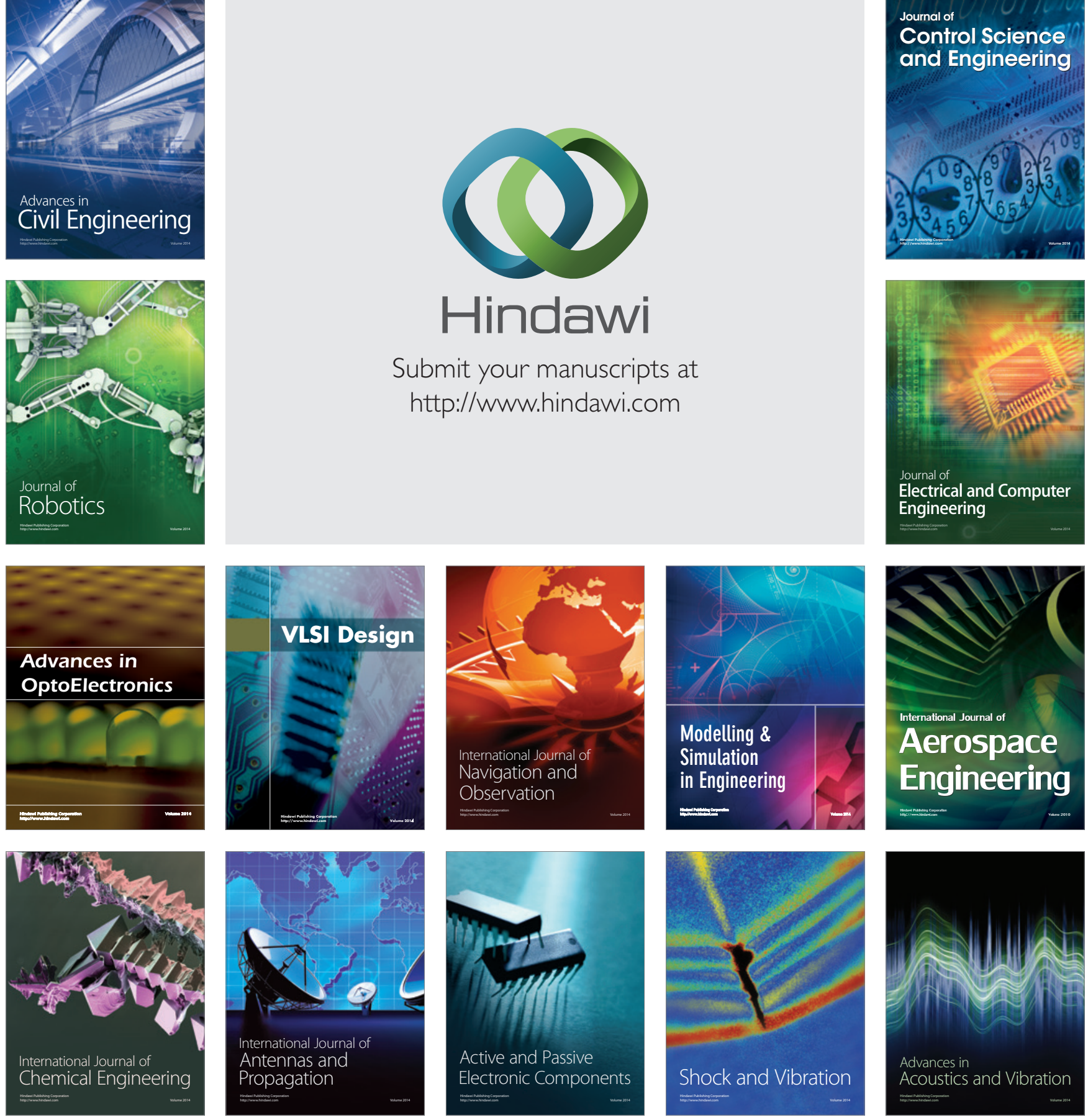